\begin{abstract}
Title of Thesis:

MOISTURE TRANSPORT THROUGH

HOUSING MATERIALS ENCLOSING

CRITICAL AUTOMOTIVE ELECTRONICS

Artur Marek Roman,

Master of Science

2019

Thesis Directed By:

Professor Bongtae Han

Department of Mechanical Engineering
\end{abstract}

In automotive electronics, humidity-sensitive electronics are encapsulated by protective housings that are attached to the car body. Typical housing materials are comprised of polymer composites, through which moisture transport occurs. The objective of this paper is to provide a predictive capability for moisture transport through automotive housings enclosing a cavity with electronic modules. The temperature-dependent moisture properties including moisture diffusivity, solubility, and saturated concentration of three housing material candidates are characterized first. Then, the analogy between heat transfer and the mass transfer is implemented to model the moisture transport into the cavity enclosed by the housing materials. To cope with the transient boundary condition at the housing material and the cavity interface, the effective volume scheme is used, treating the cavity as an imaginary polymer with an extremely large diffusivity and "equivalent solubility." The prediction is subsequently 
validated through an experimental setup designed to monitor the in-situ humidity condition inside the cavity sealed by the housing materials. The prediction and experimental results agree well with each other, which corroborates the validity of the FEA modeling and the measured moisture properties. 


\title{
MOISTURE TRANSPORT THROUGH HOUSING MATERIALS ENCLOSING CRITICAL AUTOMOTIVE ELECTRONICS
}

\author{
by \\ Artur Marek Roman \\ Thesis submitted to the Faculty of the Graduate School of the \\ University of Maryland, College Park, in partial fulfillment \\ of the requirements for the degree of \\ Master of Science \\ 2019
}

Advisory Committee:

Professor Bongtae Han, Chair

Professor Abhijit Dasgupta

Professor Patrick McCluskey 
(C) Copyright by

Artur Marek Roman

2019 


\section{Acknowledgements}

It is with immense gratitude that I acknowledge the support and help of my thesis advisor Professor Bongtae Han. His guidance has been instrumental in my academic and professional development, and will continue to guide me throughout my career. His patience, enthusiasm, and encouragement were invaluable and greatly appreciated.

Besides my advisor, I would like to thank my Professor Dasgupta and Professor McCluskey for serving on my thesis committee and for their valuable insight and feedback on my research.

I would also like to acknowledge all of my lab mates for their support along the way, including: Dr. Bulong Wu, Dr. Dae-Suk Kim, Dr. Sean Wei, Hyun-Seop Lee, Byung Kim, Jack Yang, Ryan Kim, and Sukrut Phansalkar. Particularly, I would like to thank Dr. Bulong Wu for his mentorship on this project early on in my tenure at the LOMSS lab.

Lastly, I would like to thank my friends and family for their support in the past few years. 


\section{Table of Contents}

Acknowledgements .................................................................................................................. ii

Table of Contents ....................................................................................................................... iii

List of Tables ............................................................................................................................

List of Figures....................................................................................................................... vi

Chapter 1: Introduction .................................................................................................................1

Chapter 2: Moisture Transport Fundamentals..................................................................3

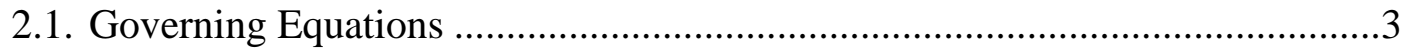

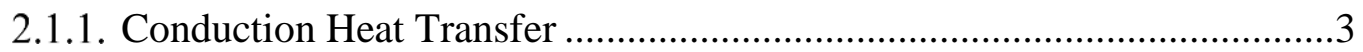

2.1.2. Diffusive Moisture Transport .................................................................

2.2. Thermal-Moisture Analogies ………………….......................................

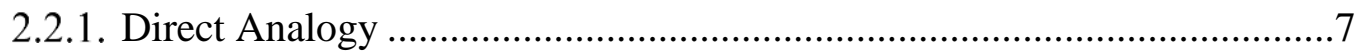

2.2.2. Normalized Analogy ....................................................................

2.2.3. Advanced Analogy …………………………….................................. 10

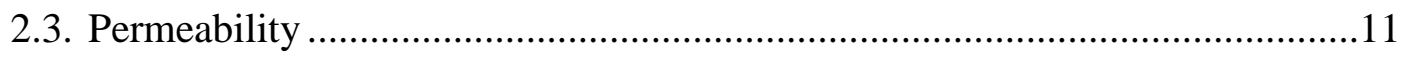

Chapter 3: Characterization of Hygroscopic Material Properties............................14

3.1. Overview of Experimental Procedures ...........................................................14

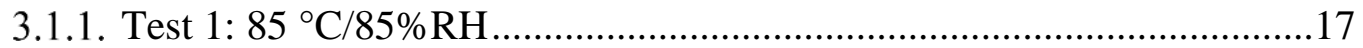

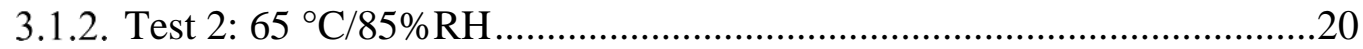

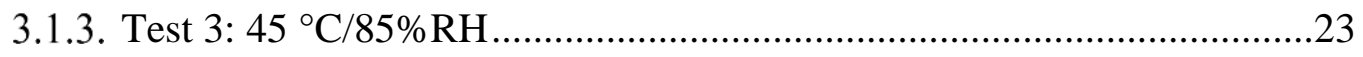

3.2. Hygroscopic Material Property Calculations ...................................................26

Chapter 4: Modeling Methodology and Experimental Validation............................34

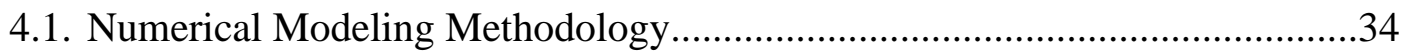

4.2. Experimental Validation of Modeling Methodology .........................................35

4.2.1. Experimental Setup .................................................................................. 36

4.2.2. Numerical Prediction of Permeation and Comparison to Experimental Data 40

Chapter 5: Implementation of the Proposed Methodology .........................................45 
5.1. Typical Enclosures for Automotive Electronics .

5.2. Numerical Prediction of Moisture Transport for Automotive Electronics

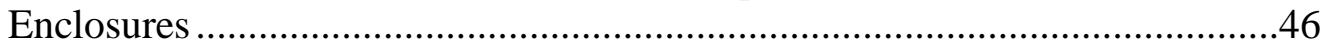

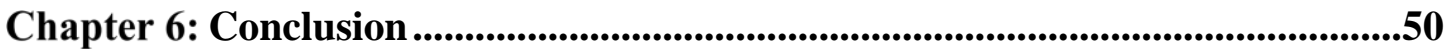




\section{List of Tables}

Table 1 Dimensions of the specimens tested at $85^{\circ} \mathrm{C} / 85 \% \mathrm{RH}$ along with the experimentally determined hygroscopic material properties. ID and CS are the inner diameter and cross section (diameter) of the O-ring, respectively.

Table 2 Dimensions of the specimens tested at $65{ }^{\circ} \mathrm{C} / 85 \% \mathrm{RH}$ along with the experimentally determined hygroscopic material properties

Table 3 Dimensions of the specimens tested at $45{ }^{\circ} \mathrm{C} / 85 \% \mathrm{RH}$ along with the experimentally determined hygroscopic material properties

Table 4 Saturated concentrations ............................................................ 28

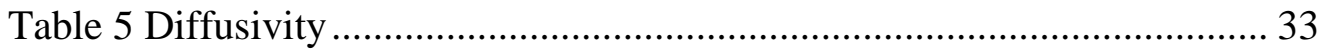

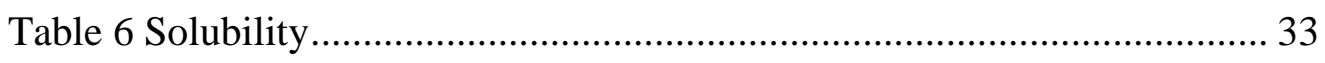

Table 7 Analogy between heat transfer and moisture diffusion [19]............. 34

Table 8 Predicted moisture properties at $75{ }^{\circ} \mathrm{C}$....................................... 40

Table 9 Initial conditions used in numerical model of the sensor experiment 43 


\section{List of Figures}

Figure 1 Depiction of moisture transport through a housing material enclosing automotive electronics. The arrows indicate the moisture transport path.

Figure 2 Infinitesimal cube element for three-dimensional mass transfer analysis. 5

Figure 3 Weight loss of the specimens due to baking at $125^{\circ} \mathrm{C}$ is shown above. These specimens will undergo moisture absorption testing at $85{ }^{\circ} \mathrm{C} / 85 \% \mathrm{RH}$. 17

Figure 4 Moisture absorption of the three specimens: (a), (b), and (c), and Orings (d) at the moisture condition of $85{ }^{\circ} \mathrm{C} / 85 \% \mathrm{RH}$

Figure 5 Weight loss of the specimens due to baking at $125^{\circ} \mathrm{C}$ is shown above. These specimens will undergo moisture absorption testing at $65^{\circ} \mathrm{C} / 85 \% \mathrm{RH}$. 20

Figure 6 Moisture absorption of the three specimens: (a), (b), and (c), and Orings (d) at the moisture condition of $65^{\circ} \mathrm{C} / 85 \% \mathrm{RH}$ 22

Figure 7 Weight loss of the specimens due to baking at $125^{\circ} \mathrm{C}$ is shown above. These specimens will undergo moisture absorption testing at $45{ }^{\circ} \mathrm{C} / 85 \% \mathrm{RH}$. 23

Figure 8 Moisture absorption of the three specimens: (a), (b), and (c), and Orings (d) at the moisture condition of $45{ }^{\circ} \mathrm{C} / 85 \% \mathrm{RH}$ 25

Figure 9 Moisture weight gain histories of three different composite polymers, each subjected to $85 \% \mathrm{RH}$ at $85^{\circ} \mathrm{C}, 65^{\circ} \mathrm{C}$, and $45^{\circ} \mathrm{C}$, respectively. The data points and solid lines represent the measurement data and Fickian predictions, respectively.

Figure 10 Saturated concentration as a function of temperature for material A

plotted in (a) and materials B and C plotted in (b). 30 
Figure 11 Temperature dependent moisture diffusivity.....

Figure 12 Temperature dependent moisture solubility 32

Figure 13 Simplified schematic of bulk moisture transport through the housing into the cavity 36

Figure 14 (a) Picture of disassembled steel sensors and (b) exploded view of experimental sensor set-up. The sensor is located at the bottom of the cavity inside the steel cylinder and is connected to a data collection box through a wire.

Figure 15 Comparisons between experimental data (discrete data points) and associated numerical predictions (solid line) for: (a) material A, (b) material B, and (c) material $\mathrm{C}$, obtained from two independent sensor tests at $75^{\circ} \mathrm{C} / 75 \% \mathrm{RH}$.

Figure 16 2-D axisymmetric (about the leftmost edge) model with initial conditions, boundary conditions, and loading at $75^{\circ} \mathrm{C} / 75 \% \mathrm{RH}$.

Figure 17 Cross-sectional view of the 3D box model with initial conditions, boundary conditions and loading. 1,404 $\mathrm{Pa}, 0 \mathrm{~Pa}$, and 49,137 $\mathrm{Pa}$ represent the initial conditions of the cavity (room condition $23{ }^{\circ} \mathrm{C} / 50 \% \mathrm{RH}$ ), the housing completely dried (0 Pa), and boundary condition of the ambient $\left(85^{\circ} \mathrm{C} / 85 \% \mathrm{RH}\right)$.

Figure 18 Numerical prediction of moisture transport through a general automotive electronics enclosure composed of material $\mathrm{A}, \mathrm{B}$, and $\mathrm{C}$, subjected to accelerated testing at $85^{\circ} \mathrm{C} / 85 \mathrm{RH}$. 48

Figure 19 Prediction of moisture transport through 3D box model under realworld moisture conditions. 49 


\section{Chapter 1: Introduction}

More electronics, including various types of sensors and imaging devices, are being utilized in automobiles to enhance safety and user experience. Some of the most technologically advanced vehicles today integrate around 450 semiconductor devices [1]. This trend is expected to continue to increase as autonomous and connected vehicles become a reality [2-5]. Autonomous vehicles will require advanced semiconductor technology to process and store massive amounts of data. Any component failures or interruption in performance may result in catastrophic safety consequences, and thus the electronics must have the highest reliability. Due to the harsh environmental conditions present in the automotive application, reliability requirements of automotive electronics are more stringent than those of consumer or industrial electronics [6].

In the past, humidity-sensitive electronics were enclosed by metal housings, but the industry has been transitioning to composite polymer housings due to their lower cost and weight [7-12]. Unlike metal, these composite polymers can contain and transport moisture [13]. Characterization of moisture-related properties of housing materials and prediction capability of the moisture transport through the materials are critical to material selection and reliability assessments of the encapsulated electronics.

To enable a preventive description of moisture-dependent behavior of the enclosed electronic modules, it is important to ensure a precise description of the humidity condition on the module surface. This condition depends on the outside environment and the permeation of moisture through the housing. 
Figure 1 shows the general configuration of an electronic module inside the car body, protected from the environment by a polymer-based housing. The conditions in the ambient environment are generally known quantities, which depend on the car and mounting location of the housing. Moisture permeates through the housing material and into the internal environment of the cavity. Once in the cavity, moisture can absorb into the electronic module and can cause reliability issues [14].

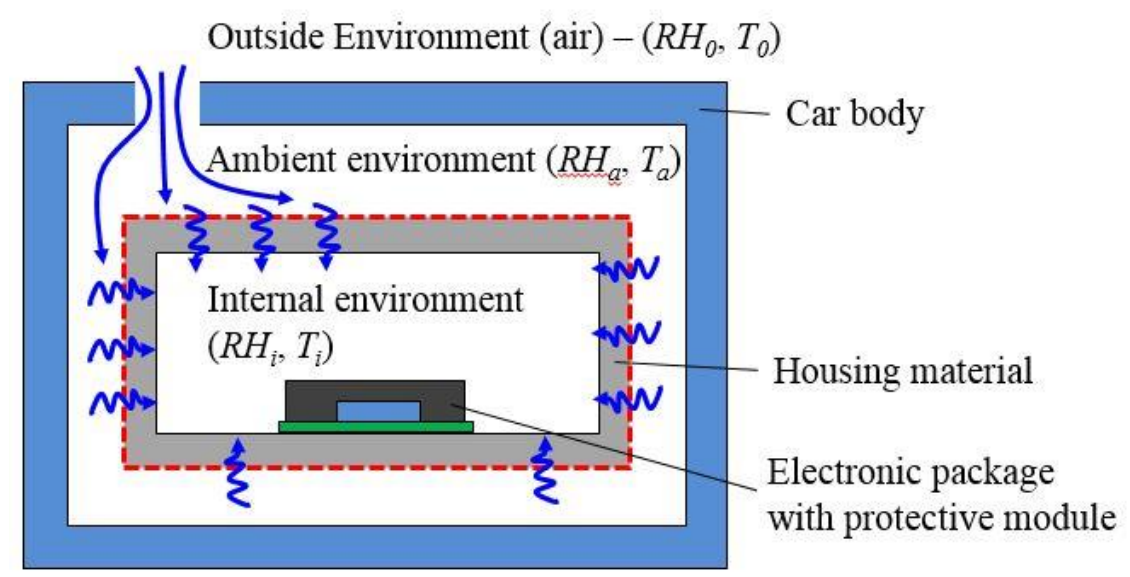

Figure 1 Depiction of moisture transport through a housing material enclosing automotive electronics. The arrows indicate the moisture transport path.

The objective of this paper is to provide a predictive capability for moisture transport through automotive housings enclosing a cavity with electronic modules. First, moisture transport fundamentals are reviewed. Then, hygroscopic material properties of three composite polymer housing materials are determined experimentally. Subsequently, existing moisture-thermal analogy fundamentals are adapted to develop a numerical prediction of moisture transport through a general housing configuration. The numerical solution is corroborated through a unique experimental setup designed to monitor the in-situ moisture condition in a cavity surrounded by housing material. 


\section{Chapter 2: $\quad$ Moisture Transport Fundamentals}

\subsection{Governing Equations}

Moisture diffusion, like heat conduction, is a diffusive process and thus has a governing equation similar to that of heat conduction. In this section, the derivation of heat diffusion equations will be briefly discussed. Then, moisture diffusion relations will be derived more rigorously. Lastly, the importance of permeation for this application (i.e., moisture transport through a polymer into a cavity) will be reviewed.

\subsubsection{Conduction Heat Transfer}

The heat flux due to conduction of heat through a material across a temperature gradient is given by Fourier's law of heat conduction. Assuming isotropic thermal conductivity ( $\nabla k=0)$, Fourier's law is expressed as [15]

$$
\boldsymbol{q}=-k \nabla T
$$

where $\boldsymbol{q}, T, \nabla$, and $k$ are the heat flux $\left(\mathrm{W} \mathrm{m}^{-2}\right)$, temperature $(\mathrm{K})$, gradient operator, and the thermal conductivity $\left(\mathrm{W} \mathrm{m} \mathrm{m}^{-1} \mathrm{~K}^{-1}\right)$, respectively. Applying the conservation of energy to a differential volume yields the general three-dimensional heat conduction equation below

$$
\frac{\partial}{\partial x}\left(k \frac{\partial T}{\partial x}\right)+\frac{\partial}{\partial y}\left(k \frac{\partial T}{\partial y}\right)+\frac{\partial}{\partial z}\left(k \frac{\partial T}{\partial z}\right)+\dot{q}=\rho C_{p} \frac{\partial T}{\partial t}
$$

where $\dot{q}$ is the volumetric heat generation $\left(\mathrm{W} \mathrm{m}^{-3}\right), \rho$ is the density $\left(\mathrm{kg} \mathrm{m}^{-3}\right)$, and $C_{p}$ is the specific heat $\left(\mathrm{J} \mathrm{kg}^{-1} \mathrm{~K}^{-1}\right)$. For isotropic thermal diffusion without heat generation, the equation (2) can be rewritten as 


$$
\rho C_{p} \frac{\partial T}{\partial t}+\nabla \cdot \boldsymbol{q}=0
$$

Substituting equation (1) into the above equation yields the final simplified form of conductive heat transfer for an isotropic thermal conductive material without heat generation

$$
\rho C_{p} \dot{T}=\nabla \cdot(k \nabla T) \text { or } \frac{\partial T}{\partial t}=\alpha \nabla^{2} T
$$

where $\alpha$ is the thermal diffusivity $\left(\mathrm{m}^{2} \mathrm{~s}^{-1}\right)$ and is defined as $\alpha=k / \rho C_{p}$.

\subsubsection{Diffusive Moisture Transport}

In general, the diffusion of water molecules into polymers follow Fick's laws [16]. The steady state mass (moisture) diffusion through a solid of isotropic and uniform diffusivity $(\nabla D=0)$ can be described by Fick's $1^{\text {st }}$ law as

$$
\boldsymbol{J}=-D \nabla C
$$

where $\boldsymbol{J}, D$, and $C$ are the mass flux $\left(\mathrm{kg} \mathrm{m}^{-2} \mathrm{~s}^{-1}\right)$, diffusivity coefficient $\left(\mathrm{m}^{2} \mathrm{~s}^{-1}\right)$, and moisture concentration $\left(\mathrm{kg} \mathrm{m}^{-3}\right)$, respectively. The conservation of mass enumerated in equation (6) is then applied to an infinitesimal volume, as shown in Figure 2, to obtain the general moisture diffusion equation [17]. 


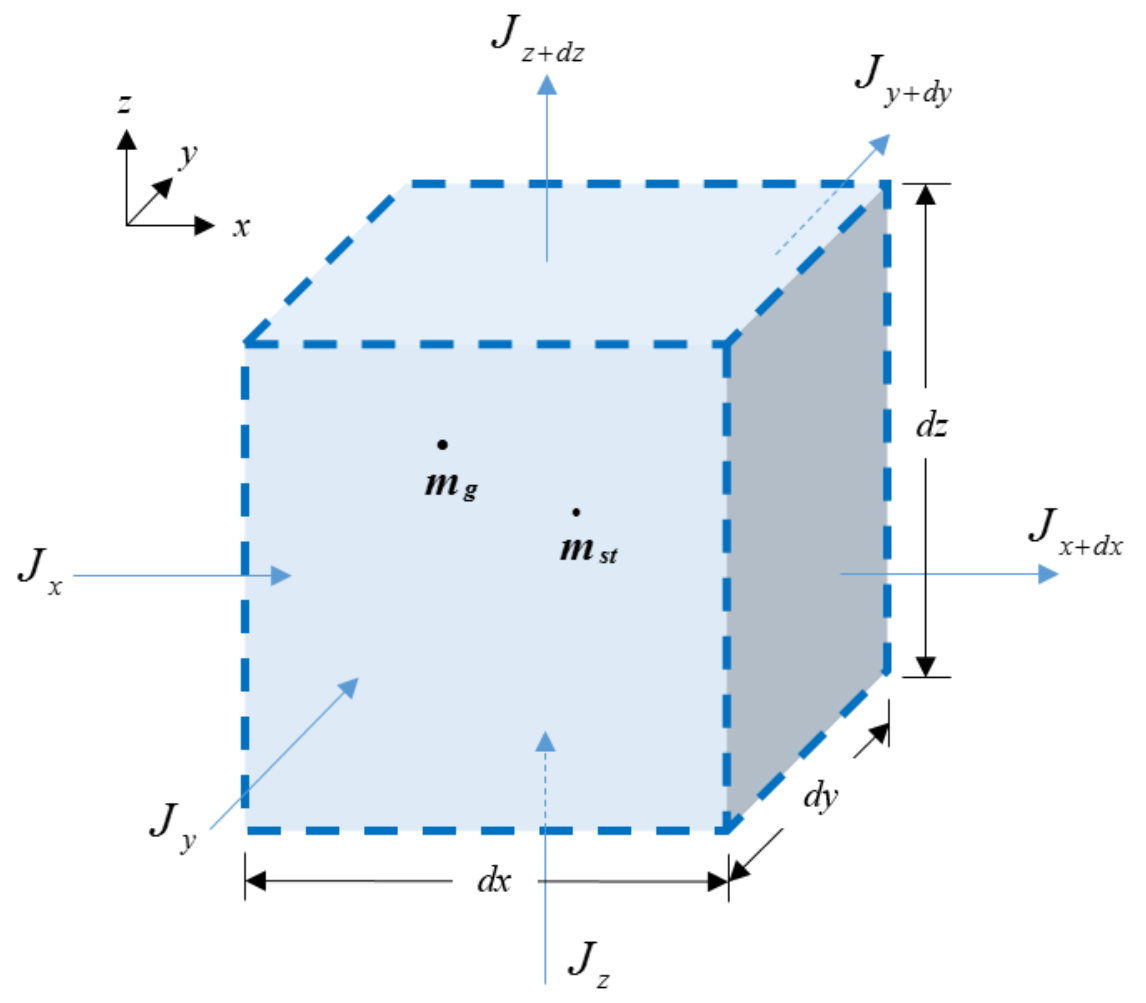

Figure 2 Infinitesimal cube element for three-dimensional mass transfer analysis

$$
\dot{m}_{\text {in }}-\dot{m}_{\text {out }}+\dot{m}_{g}=\dot{m}_{s t}
$$

In the above equation, $\dot{m}_{g}$ and $\dot{m}_{s t}$ are the rates at which the mass of some species (e.g. water molecule) is generated and the rate at which the mass of that species is stored, respectively (both in units of $\mathrm{kg} \mathrm{s}^{-1}$ ) [18]. The generation of a species refers to appearance of a species due to a chemical reaction, such as the recombination reaction of hydrogen and oxygen resulting in $\mathrm{H}_{2} \mathrm{O}$ [15]. The mass conservation is then expressed in terms of mass fluxes, as shown below where $\dot{M}_{g}$ is the volumetric species generation

$$
\begin{aligned}
& \left(J_{x+d x}-J_{x}\right) d y d z+\left(J_{y+d y}-J_{y}\right) d x d z+\left(J_{z+d z}-J_{z}\right) d x d y+ \\
& \dot{M}_{g} d x d y d z=d x d y d z \frac{\partial C}{\partial t}
\end{aligned}
$$


Subsequently, a $1^{\text {st }}$ order Taylor expansion is used to express the mass flux through one cube face to the opposite cube face. This expansion is shown below for the fluxes in each direction as [18]

$$
J_{x+d x}=J_{x}+\frac{\partial J_{x}}{\partial x} d x ; J_{y+d y}=J_{y}+\frac{\partial J_{y}}{\partial y} d y ; J_{z+d z}=J_{z}+\frac{\partial J_{z}}{\partial z} d z
$$

After plugging equation (8) into equation (7), simplifying, and dividing all the terms in the equation by the infinitesimal volume $(d x d y d z)$, the following relation is obtained [15]

$$
\frac{\partial}{\partial x}\left(D_{x} \frac{\partial C}{\partial x}\right)+\frac{\partial}{\partial y}\left(D_{y} \frac{\partial C}{\partial y}\right)+\frac{\partial}{\partial z}\left(D_{z} \frac{\partial C}{\partial z}\right)+\dot{m}_{g}=\frac{\partial C}{\partial t}
$$

Assuming no substance generation and uniform diffusivity, the final form of the equation can be expressed as

$$
\frac{\partial C}{\partial t}=D \nabla^{2} C
$$

In many polymer systems, a linear relationship exists between the ambient vapor pressure and the corresponding equilibrium concentration [19]. This relationship is known as Henry's law, and is shown as:

$$
C=S p_{v}
$$

where $S$ is the solubility $\left(\mathrm{kg} \mathrm{m}^{-3} \mathrm{~Pa}^{-1}\right)$ and $p_{v}$ is the ambient vapor pressure $(\mathrm{Pa})$, which is defined as

$$
p_{v}=p_{s a t} \cdot(R H \%)
$$

where $p_{\text {sat }}$ is the saturated vapor pressure of water, which can be obtained from steam tables, and $R H \%$ is the fraction of relative humidity (between 0 and 1 ). 
Diffusivity and solubility used in the above equations are both known to follow the Arrhenius relationship, expressed as [20]:

$$
D=D_{0} \exp \left(-\frac{E_{D}}{R T}\right) \text { and } S=S_{0} \exp \left(-\frac{E_{S}}{R T}\right)
$$

where $D_{0}\left(\mathrm{~m}^{2} / \mathrm{s}^{2}\right)$ and $E_{D}(\mathrm{~J} / \mathrm{mol})$ are the constant and the activation energy of diffusivity, respectively; $R$ is the universal gas constant; $S_{0}$ and $E_{S}$ are the constant $\left(\mathrm{s}^{2} / \mathrm{m}^{2}\right)$ and the activation energy $(\mathrm{J} / \mathrm{mol})$ of solubility, respectively; and $T$ is the temperature $(\mathrm{K})$. Combining the temperature dependence of diffusivity and solubility with the equation of permeation yields the Arrhenius form of permeability as [20]

$$
P=P_{0} \exp \left(-\frac{E_{P}}{R T}\right)
$$

\subsection{Thermal-Moisture Analogies}

The analogies between heat transfer and moisture diffusion are well established and will be reviewed below.

\subsubsection{Direct Analogy}

The direct analogy originates from comparing the terms of equations (4) and (10) [19]. Both governing equations have identical forms when the density, $\rho$, and specific heat, $C_{p}$, are set to "unity" [21]. It is easy to see that the field variable for heat transfer is temperature, $T$, while for moisture transport the field variable is $C$, concentration. Similarly, the thermal diffusivity for conduction heat transfer is analogous to the diffusivity for moisture diffusion.

It is important to note the limitations of this analogy. Because diffusivity is a strong function of temperature, the direct analogy requires a spatially (but not 
necessarily temporally) constant temperature field. Additionally, both the governing equations for both thermal and moisture diffusion were derived assuming the gradient of thermal conductivity and moisture diffusivity were both zero. Thus, the direct analogy is only valid for only homogenous materials. A major drawback of this analogy is its inability to handle multi-material systems due to the inherent moisture concentration discontinuity at the interface. Between different polymeric materials, the moisture concentration is discontinuous, as the maximum moisture a polymer can absorb is a material property [19]. In order to numerically solve a multimaterial problem, normalized field variables, which are continuous across the interface, are necessary and will be introduced in the following subsection.

\subsubsection{Normalized Analogy}

The normalized analogy, on the other hand, effectively deals with the inherent moisture concentration discontinuity at the interface between two different materials [22]. Because moisture concentration is a material property, at the same temperature and relative humidity two materials with different solubilities will saturate with a different amount of moisture according to Henrys Law. The Nernst distribution law, shown below, governs the moisture concentration at the interface between two materials [23]

$$
\chi=\frac{C_{1}}{C_{2}}=\frac{S_{1}}{S_{2}}
$$

where $C_{1}, S_{1}$ and $C_{2}, S_{2}$ are the moisture concentration and solubility of the first and second materials, respectively, at a particular temperature. A continuous field variable 
across a bimaterial interface can then be obtained by manipulating equation (15) and considering Henry’s law (11) to obtain

$$
p_{v}=\frac{C_{1}}{S_{1}}=\frac{C_{2}}{S_{2}}
$$

where $p_{v}$ is referred to as the "normalized concentration," partial vapor pressure, or wetness, and has units of $\mathrm{Pa}[21]$. The above relation can be then substituted into equation (10) to obtain the governing equation of transient moisture transport as

$$
\frac{\partial S}{\partial t} p_{v}+\frac{\partial p_{v}}{\partial t} S=\nabla \cdot\left(D S \nabla p_{v}\right) \Rightarrow S \dot{p}_{v}=\nabla \cdot\left(P \nabla p_{v}\right)
$$

where $\partial S / \partial t=\nabla S=0$ in the case of a uniform and time-independent temperature field. $P$ is defined as the permeability coefficient $(P=D S)$ and will be discussed in the following section. Equation (17) is similar in form to equation (4) and therefore a thermal-moisture analogy may be constructed. The field variable for heat transfer is temperature, $T$, while for moisture transport the field variable is $p_{v}$, normalized concentration. Similarly, the thermal diffusivity for conduction heat transfer is analogous to the permeability coefficient for moisture diffusion. Lastly, the solubility, $S$, in this analogy would be equivalent to $\rho C_{p}$.

Like the direct analogy, the normalized analogy has its limitations [24]. Although its domain of applications include multimaterial problems, it was derived assuming the solubility does not vary spatially $(\nabla S=0)$ or temporally $(\dot{T}=0)$. Because solubility is a function of temperature, this means the normalized analogy may only be used for isothermal time-independent loading applications. 


\subsubsection{Advanced Analogy}

The advanced analogy is based on the special case when $S \times p_{\text {sat }}$ is not a function of temperature [21]. This means that upon combining equations (11) and (12), $C_{\text {sat }}$ is a linear function of relative humidity. Some studies reported that packaging materials used exhibited this phenomena, allowing for an application of the advanced analogy $[21,25]$. In this analogy, Henry's law can be rewritten as the following, with $M$ being referred to as the "modified solubility"

$$
C_{\text {sat }}=M \times(R H \%)
$$

From this relation, a new normalized concentration, $\varphi=C / M$, independent of temperature can be obtained. Similar to the normalized analogy derivation, this normalized variable is plugged into Fick's $2^{\text {nd }}$ law (10) to obtain the equation relating thermal diffusion to moisture diffusion using the advanced analogy

$$
\frac{\partial M}{\partial t} \varphi+\frac{\partial \varphi}{\partial t} M=\nabla \cdot\left(D M \nabla p_{v}\right) \Rightarrow M \dot{\varphi}=\nabla \cdot(D M \nabla \varphi)
$$

Like the normalized analogy, this analogy is continuous across the interface between two materials. Unlike the normalized analogy, the advanced analogy can be used for both non-uniform temporally and spatially thermal loading conditions due to the modified solubility's invariance to temperature. It is important to note that the boundary conditions must be in terms of relative humidity rather than pressure, and that the aforementioned linear relationship between saturated concentration and relative humidity must be verified experimentally before utilizing the analogy. 


\subsection{Permeability}

Permeability is the key material property for moisture transport through housing materials, as it governs the amount of gas that passes through the housing at given conditions. Permeation of gas through material occurs through three main steps: (a) adsorption of permeating species on polymer surface, (b) diffusion of species through the material, and (c) desorption from the other surface of the material [26]. In many practical applications, the moisture concentration on either side of the housing may be unknown, but the vapor pressure on each side can be measured [27]. To obtain mass flux in terms of vapor pressure, Henry's law (11) is plugged into Fick's first law (5) (for an isothermal problem $\nabla S=0$ ), yielding

$$
\boldsymbol{J}=-D S \nabla p_{v}-D p_{v} \nabla S=-P \nabla p_{v}
$$

where $P$ is the permeability coefficient (s) and is defined as the product of diffusivity and solubility $(P \equiv D \cdot S)$.

From the above relation, it is clear that the mass flux $\boldsymbol{J}$ through the polymer is directly proportional to permeability and driven by the difference in moisture vapor pressure on either side of the material. The permeability coefficient is independent of the housing thickness and the permeation rate is inversely proportional to the housing thickness [26].

There are numerous methods and standards for measuring the permeability coefficient of a material [28]. Most of the experimental setups used to measure permeability can be grouped into two main categories: gas transmission tests and sorption-desorption tests $[27,29]$. The former method is further broken down into two experimental setups: (a) gas permeation through a flat material into a chamber of fixed 
volume, and (b) gas permeation through a flat material into a flowing stream at fixed pressure. These involve solving a one-dimensional version of equation (20) for $P$, after separating variables and integrating. The resulting equation is widely used in literature and is shown below

$$
\boldsymbol{J}=-P \frac{p_{v, 2}-p_{v, 1}}{x}
$$

where $p_{v, 2}$ and $p_{v, 1}$ are the partial vapor pressures on each side of the housing, and $x$ is the housing thickness. Sorption-desorption experiments, on the other hand, involve measuring a specimen's weight variation (uptake or loss) as a function of time until the weight change reaches zero, and steady state is reached [27, 30]. From the absorption data, $D$ and $S$ can be determined, and are multiplied together to obtain $P$.

The units of permeability can often be confusing and vary based on experimental procedure. One study found 29 different dimensions of permeability used throughout literature [31]. In the case of gas transmission tests, the above equation is solved for $P$, yielding the following dimensions [26]:

$$
P=\frac{\text { (amount of gas under stated conditions) (membrane thickness) }}{\text { (membrane area) (time) (driving pressure) }}
$$

which can be reduced down to seconds. These units agree with the sorption-desorption method of determining permeability (multiplying $D$ by $S$ ). For many thin film systems, the transient behavior of moisture transport through the material is very short, and therefore permeation is generally governed by the steady state relation and measured by gas transmission tests. For thick structural materials, such as those used in housings to protect automotive electronics, transient moisture transport behavior must be considered. 
The governing equation for transient moisture transport in terms of moisture concentration was shown in the previous section to be (10). To obtain the relation in terms of vapor pressure, equation (10) is combined with equation (11) yielding

$$
\frac{\partial S}{\partial t} p_{v}+\frac{\partial p_{v}}{\partial t} S=\nabla \cdot\left(P \nabla p_{v}\right) \Rightarrow S \dot{p}_{v}=\nabla \cdot\left(P \nabla p_{v}\right)
$$

To the best of the author's knowledge, no closed form solution is available to the equation above, and it will therefore be solved numerically. 


\section{Chapter 3: Characterization of Hygroscopic Material Properties}

\subsection{Overview of Experimental Procedures}

Three glass fiber-reinforced polymers, termed material A, B, and C, were tested as potential housing materials for the automotive application. Material A was comprised of a particular compound with $35 \%$ glass fiber content. Materials B and C were both made from the same compound (different from material A) with $30 \%$ fiber content. The difference between materials B and C was that material B was stabilized against hydrolysis whereas material $\mathrm{C}$ was not. For this analysis, the fiber-reinforced polymer specimens were approximated to have isotropic diffusivity, despite containing fibers in the polymer matrix. As will be shown later in this paper, this approximation was shown to be reasonable as the modeling methodology was experimentally verified.

Permeability of three housing materials was determined through simple moisture absorption experiments. Three block-shaped housing materials, each $30 \mathrm{~mm}$ by $30 \mathrm{~mm}$ with thicknesses varying from $1 \mathrm{~mm}$ to $4 \mathrm{~mm}$ were first dried at $125{ }^{\circ} \mathrm{C}$ to remove any initial moisture content. Afterwards, the specimens were subjected to an environment of $85 \% \mathrm{RH}$ at three different temperatures: $85{ }^{\circ} \mathrm{C}, 65^{\circ} \mathrm{C}$, and $45^{\circ} \mathrm{C}$. An environmental chamber (SH-241, ESPEC) was used to provide controlled humid environments. Weight gain was periodically measured with a high-precision balance (PI-225D, Denver Instruments) until the weight remained unchanged for an extended period of time. Two specimens per material were tested at each of the three humidity conditions to ensure precise data was obtained. Specimen thickness was chosen with an aim to get enough measurements (approximately nine) in the transient portion (first 
90\%) of moisture absorption curve to ensure accurate calculation of diffusivity. Not having enough data points in the transient portion of the absorption could result in inaccurate calculations of diffusivity. As the temperature associated with the moisture condition, the specimen thickness generally decreases to maintain enough measurements within the transient portion of the absorption curve. This is due to the fact that at higher temperatures, diffusivity of the polymers are exponentially higher, as described by the Arrhenius relation in equation (13). More details pertaining to the diffusivity calculation will be discussed in the following section.

The moisture weight gain is calculated using the following equation [32].

$$
w^{\%}(t)(\text { in } \% w t)=100 \times \frac{w(t)-w_{d r y @ 125^{\circ} \mathrm{C}}}{w_{d r y @ 125^{\circ} \mathrm{C}}}
$$

where $w$ is the weight of the specimen in $\mathrm{kg}$. The moisture concentration is calculated by dividing the weight gain (in $\mathrm{kg}$ ) by the volume of the specimen. Once the specimen saturates and does not gain any more moisture (weight), its saturated moisture concentration can be calculated from the following equation.

$$
C_{\text {sat }}=w_{\text {sat }}^{\%} \frac{w_{d r y} @ 125^{\circ} \mathrm{C}}{V}
$$

where $w_{\text {sat }}^{\%}$ is the saturated weight gain percentage, obtained by plugging in the steady state saturated weight for $w(t)$ into the equation (24) above.

In the following subsections, results from the absorption tests at the three moisture conditions are shown. The raw data containing specimen weights as a function of time are transformed using Equation (24) to show a more general percent weight gain/loss, relative to the dried specimens at $125^{\circ} \mathrm{C}$. 
The weight gain (in \% weight) was plotted as a function of time for the baking of the three materials and O-rings at $125{ }^{\circ} \mathrm{C}$ and is shown below. Each of the data points in the figure represent a weight measurement. When measuring the weight loss of a specimen during baking, the other specimens which were also taken out of the baking chamber were placed into a desiccator to prevent weight gain. The O-rings were tested separately from the six block specimens but are shown on the same graph for convenience.

First, the data obtained during baking is shown. Its purpose is to make sure the material is fully baked before being subject to the moisture conditions. Then, the data from the moisture absorption experiments for each material are shown. Lastly, a table providing the specimen dimensions, average $\mathrm{C}_{\text {sat }}$, and average diffusivity obtained from the two specimens at each moisture condition are shown. The calculations of the hygroscopic material properties are described in more detail in the following section. 


\subsubsection{Test 1: $85^{\circ} \mathrm{C} / 85 \% R H$}

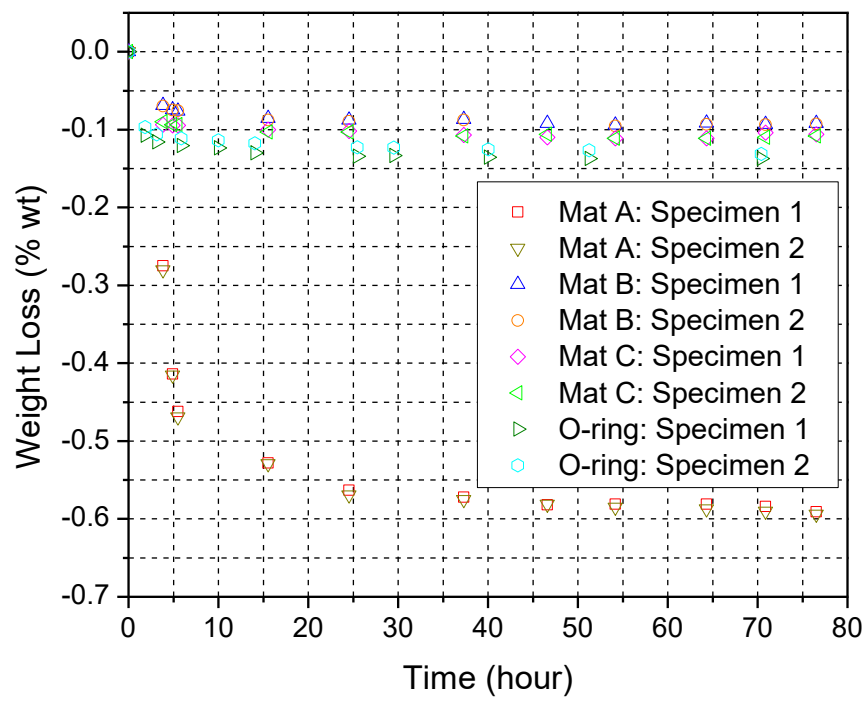

Figure 3 Weight loss of the specimens due to baking at $125^{\circ} \mathrm{C}$ is shown above. These specimens will undergo moisture absorption testing at $85{ }^{\circ} \mathrm{C} / 85 \% \mathrm{RH}$.

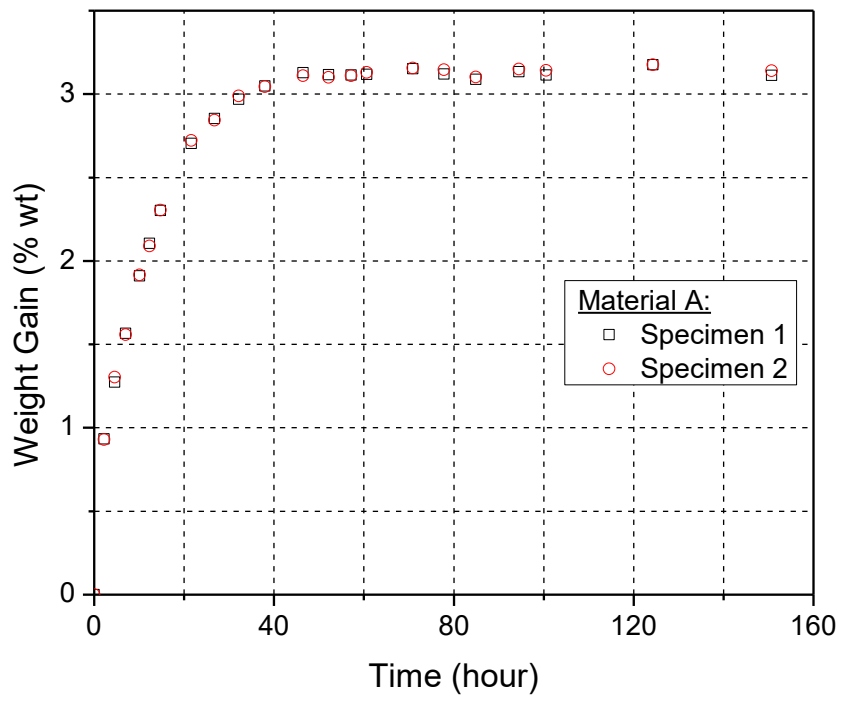

(a) 


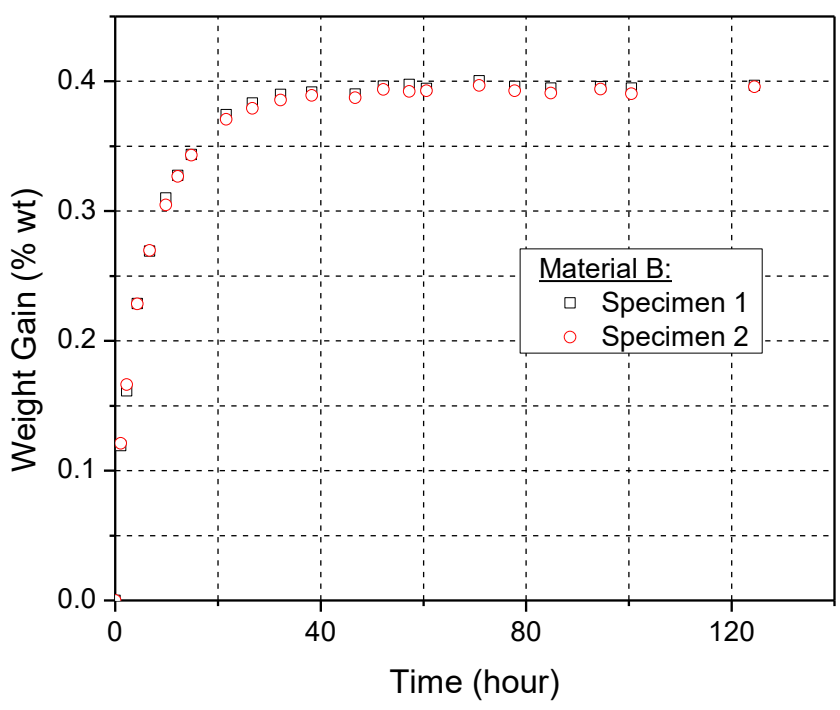

(b)

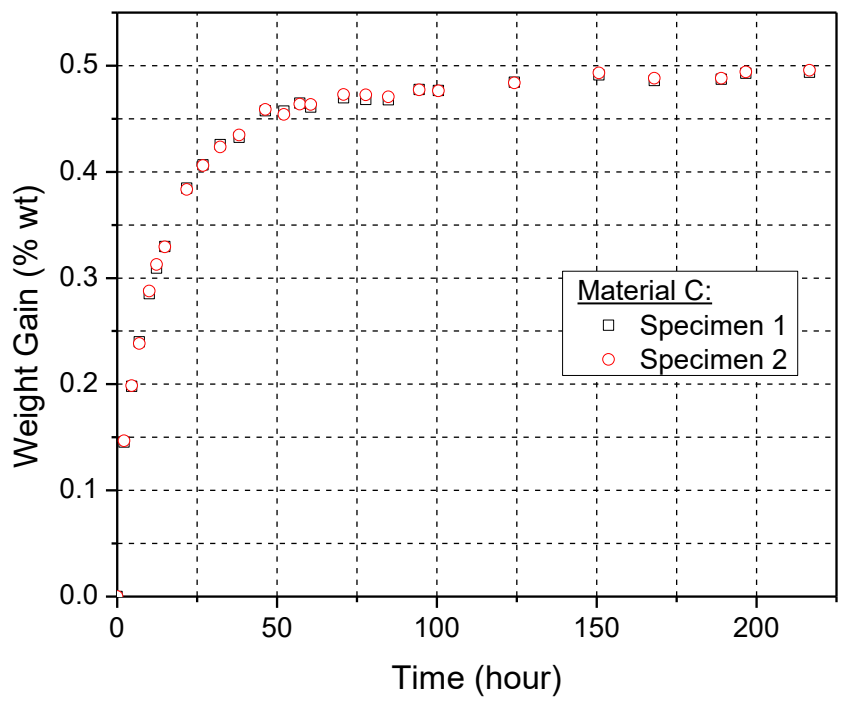

(c) 


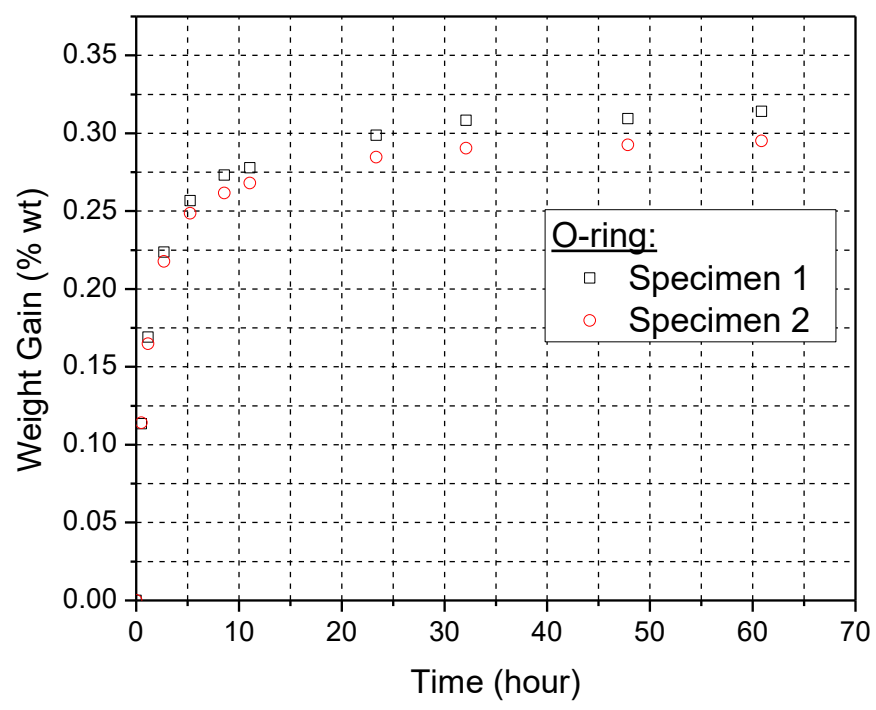

(d)

Figure 4 Moisture absorption of the three specimens: (a), (b), and (c), and O-rings (d) at the moisture condition of $85{ }^{\circ} \mathrm{C} / 85 \% \mathrm{RH}$

Table 1 Dimensions of the specimens tested at $85{ }^{\circ} \mathrm{C} / 85 \% \mathrm{RH}$ along with the experimentally determined hygroscopic material properties. ID and CS are the inner diameter and cross section (diameter) of the O-ring, respectively.

\begin{tabular}{|c|c|c|c|}
\hline \multirow{2}{*}{ Material } & \multirow{2}{*}{$\begin{array}{c}\text { Dimension } \\
(\mathrm{mm} \times \mathbf{m m} \times \mathbf{m m})\end{array}$} & \multicolumn{2}{|c|}{$85{ }^{\circ} \mathrm{C} / 85 \%$ RH Test } \\
\hline & & $D\left(\mathrm{~mm}^{2} / \mathrm{sec}\right)$ & $\mathrm{C}_{\text {sat }}(\% \mathrm{wt})$ \\
\hline $\mathrm{A}$ & $30 \times 30 \times 2$ & $7.84 \mathrm{E}-6$ & 3.13 \\
\hline $\mathrm{B}$ & $30 \times 30 \times 3$ & $3.08 \mathrm{E}-5$ & 0.39 \\
\hline $\mathrm{C}$ & $30 \times 30 \times 3$ & $1.37 \mathrm{E}-5$ & 0.49 \\
\hline O-ring & ID: $23 \mathrm{~mm} \mid \mathrm{CS}: 3.5 \mathrm{~mm}$ & $5.18 \mathrm{E}-5$ & 0.30 \\
\hline
\end{tabular}




\subsubsection{Test 2: $65^{\circ} \mathrm{C} / 85 \% R H$}

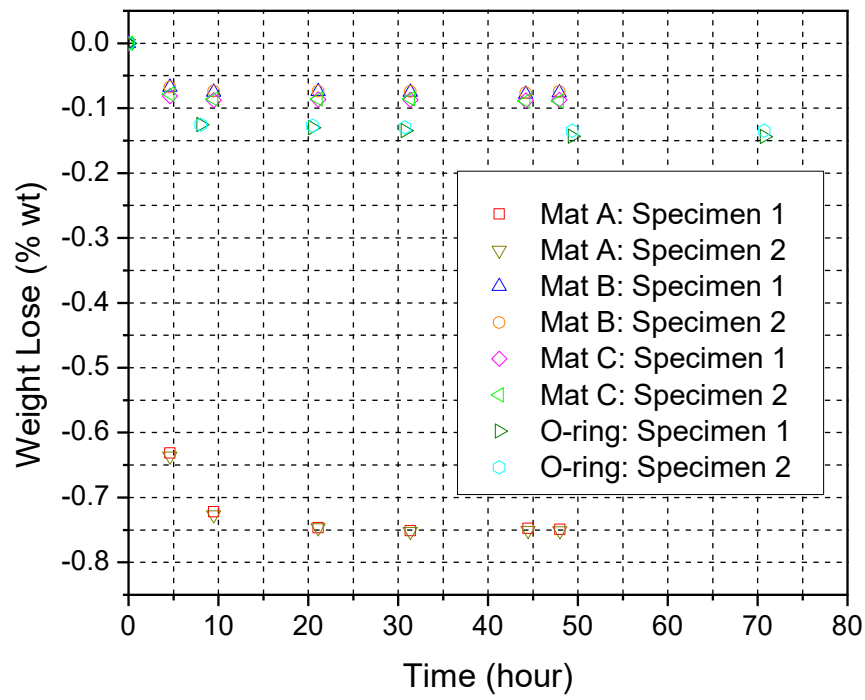

Figure 5 Weight loss of the specimens due to baking at $125^{\circ} \mathrm{C}$ is shown above. These specimens will undergo moisture absorption testing at $65{ }^{\circ} \mathrm{C} / 85 \% \mathrm{RH}$.

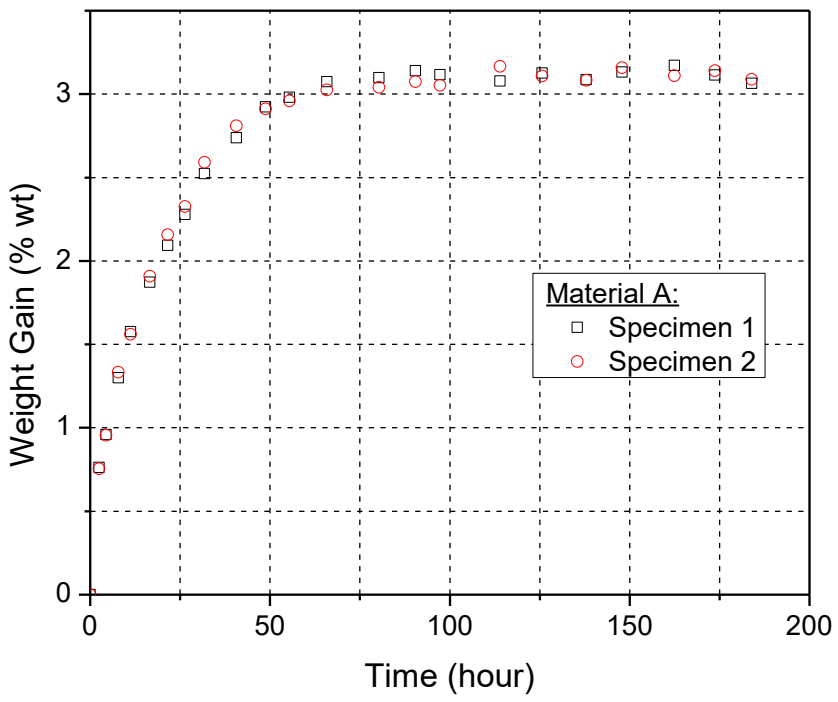

(a) 


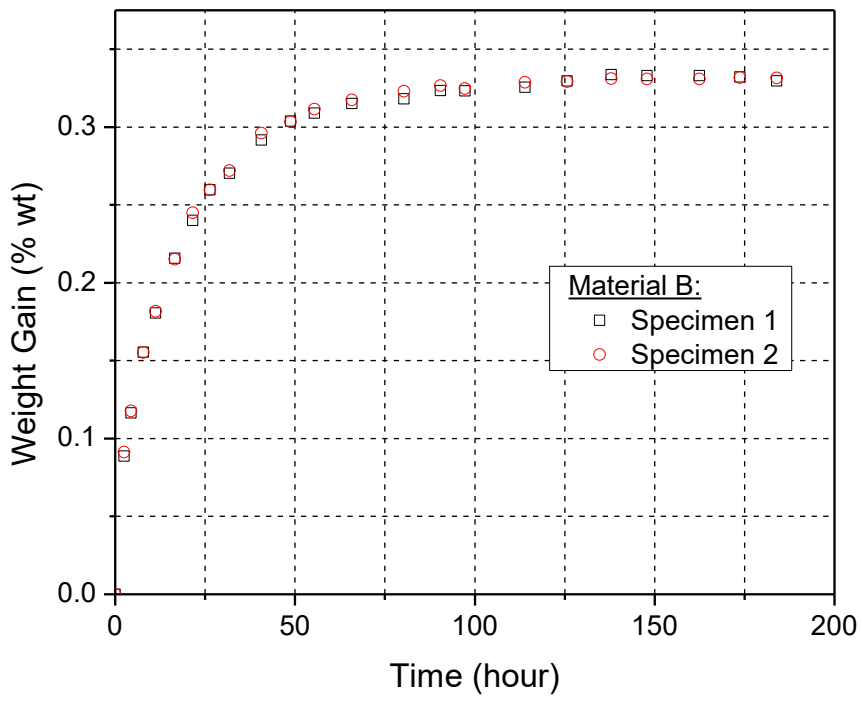

(b)

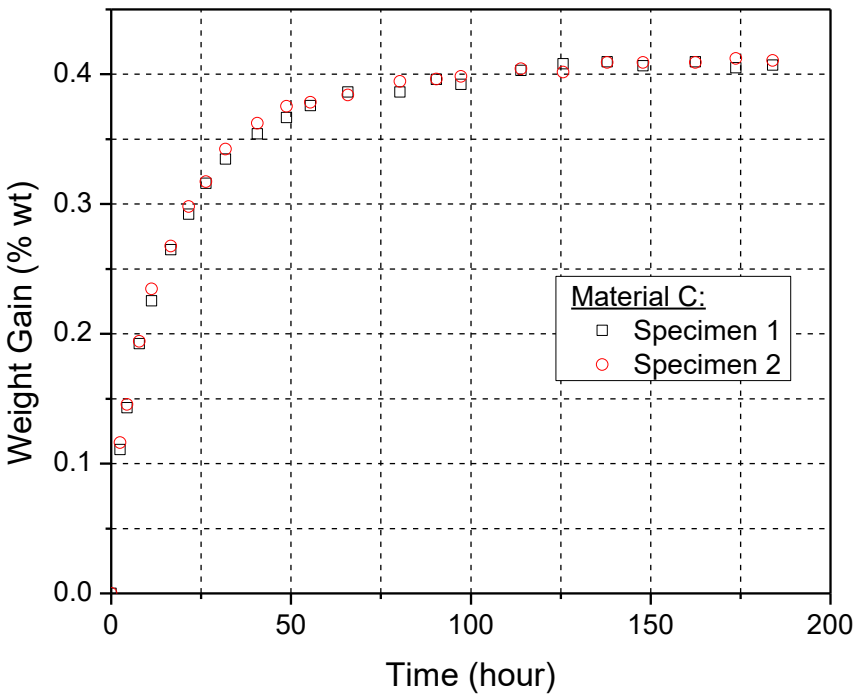

(c) 


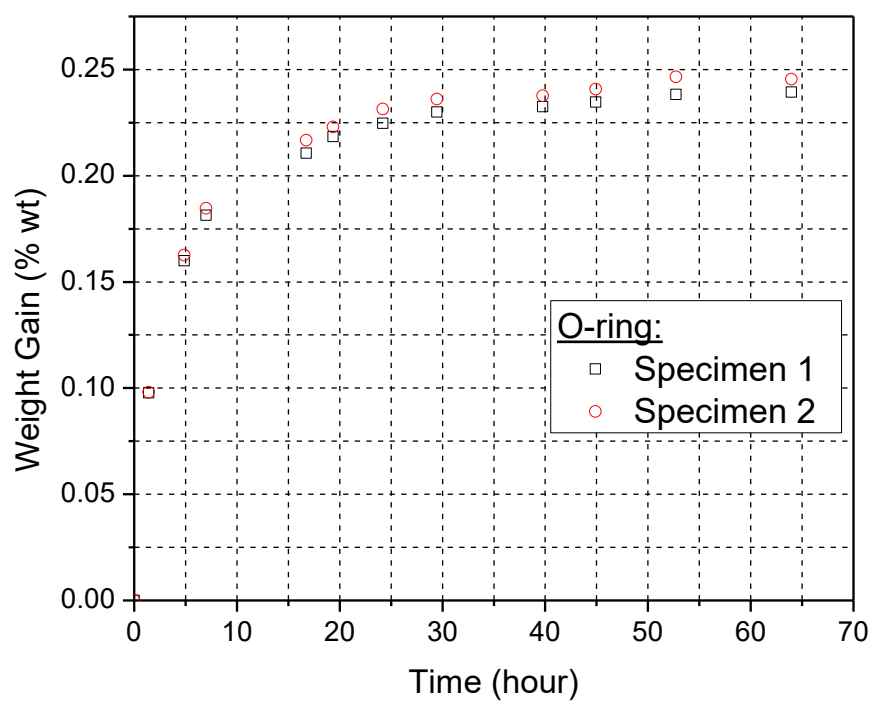

(d)

Figure 6 Moisture absorption of the three specimens: (a), (b), and (c), and O-rings (d) at the moisture condition of $65^{\circ} \mathrm{C} / 85 \% \mathrm{RH}$

Table 2 Dimensions of the specimens tested at $65{ }^{\circ} \mathrm{C} / 85 \% \mathrm{RH}$ along with the experimentally determined hygroscopic material properties

\begin{tabular}{|c|c|c|c|}
\hline \multirow{2}{*}{ Material } & \multirow{2}{*}{$\begin{array}{c}\text { Dimension } \\
(\mathbf{m m} \times \mathbf{m m} \times \mathbf{m m})\end{array}$} & \multicolumn{2}{|c|}{$\mathbf{6 5}^{\mathbf{}} \mathbf{C} / \mathbf{8 5} \% \mathbf{R H}$ Test } \\
\cline { 3 - 4 } & $30 \times 30 \times 1.5$ & $\mathbf{D}(\mathbf{m m} / \mathbf{s e c})$ & $\mathbf{C}_{\mathbf{s a t}} \mathbf{( \% \mathbf { w t } )}$ \\
\hline $\mathrm{A}$ & $30 \times 30 \times 3$ & $2.70 \mathrm{E}-6$ & 3.12 \\
\hline $\mathrm{B}$ & $30 \times 30 \times 2$ & $1.16 \mathrm{E}-5$ & 0.33 \\
\hline $\mathrm{C}$ & $5.02 \mathrm{E}-6$ & 0.41 \\
\hline O-ring & ID: $23 \mathrm{~mm} \mid \mathrm{CS}: 3.5 \mathrm{~mm}$ & $2.00 \mathrm{E}-5$ & 0.24 \\
\hline
\end{tabular}




\subsubsection{Test $3: 45^{\circ} \mathrm{C} / 85 \% R H$}

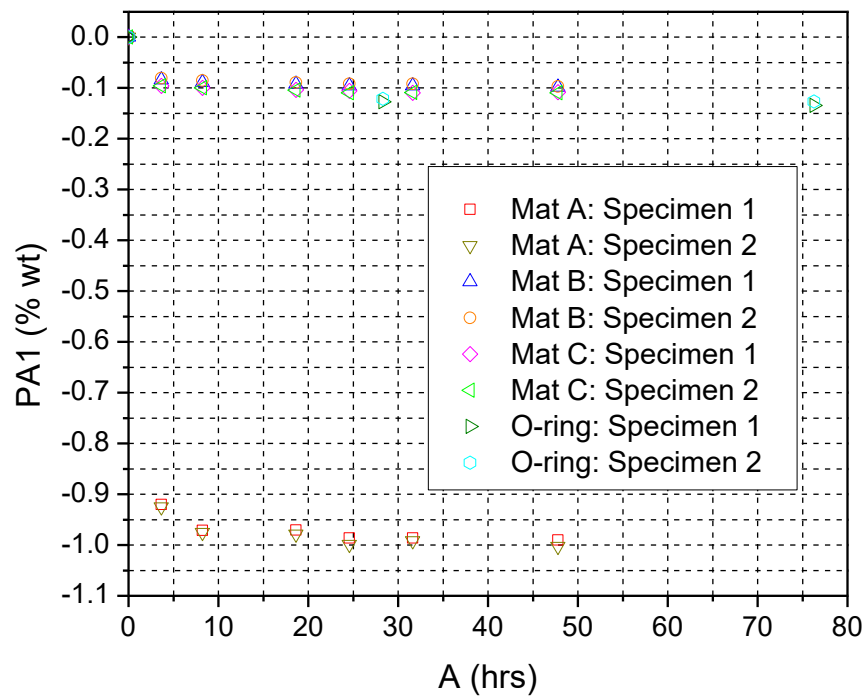

Figure 7 Weight loss of the specimens due to baking at $125^{\circ} \mathrm{C}$ is shown above. These specimens will undergo moisture absorption testing at $45{ }^{\circ} \mathrm{C} / 85 \% \mathrm{RH}$.

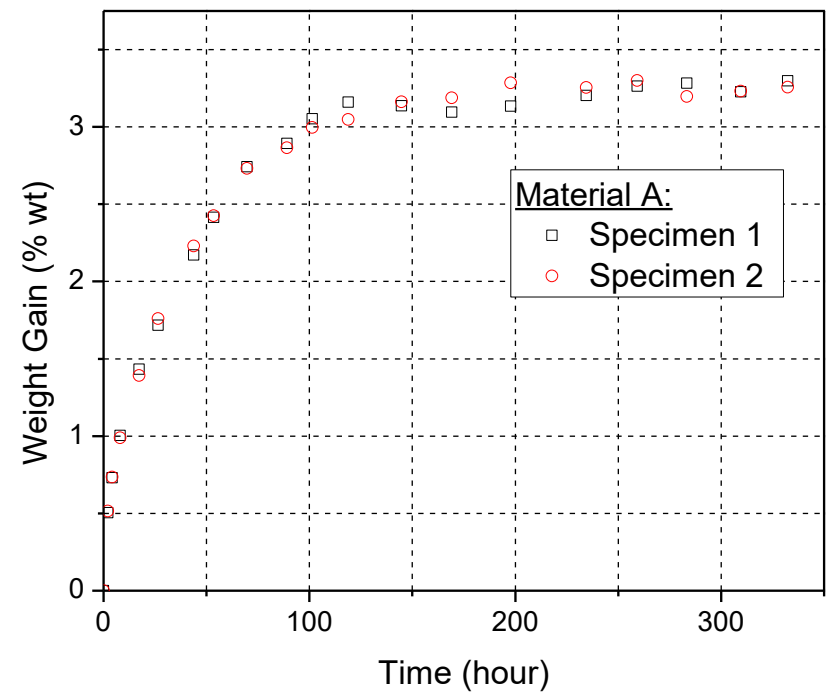

(a) 


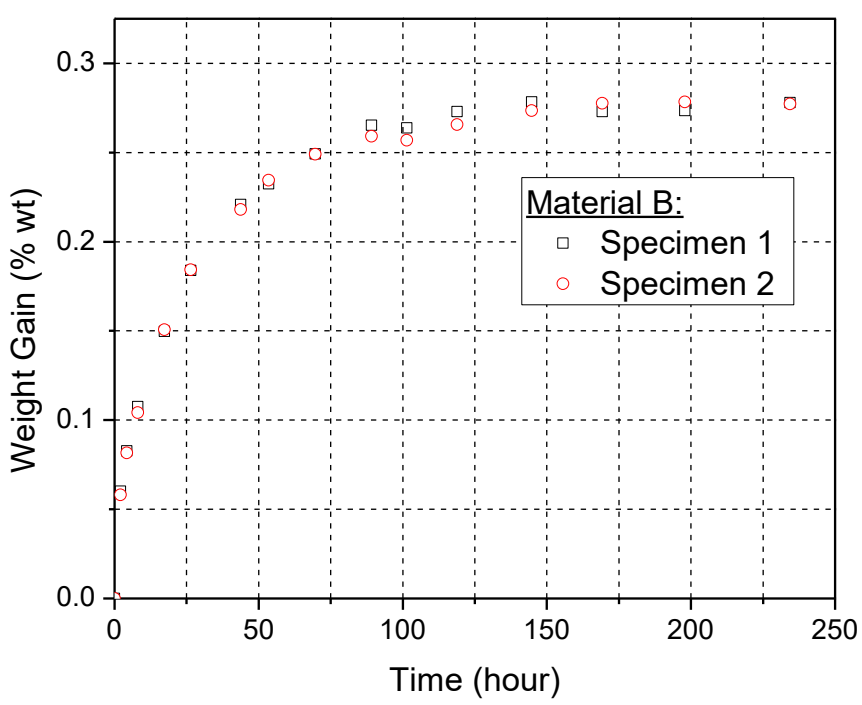

(b)

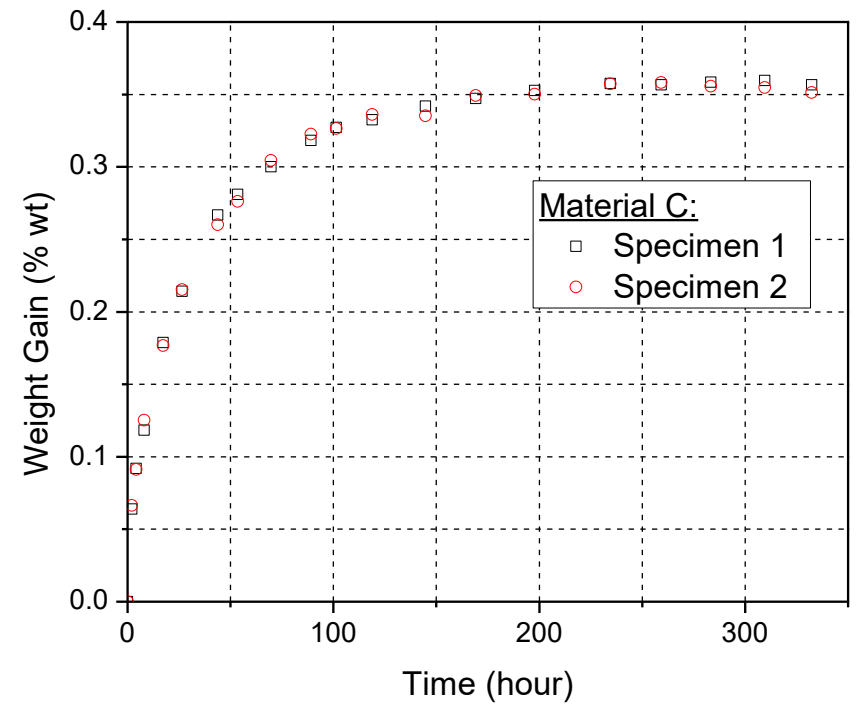

(c) 


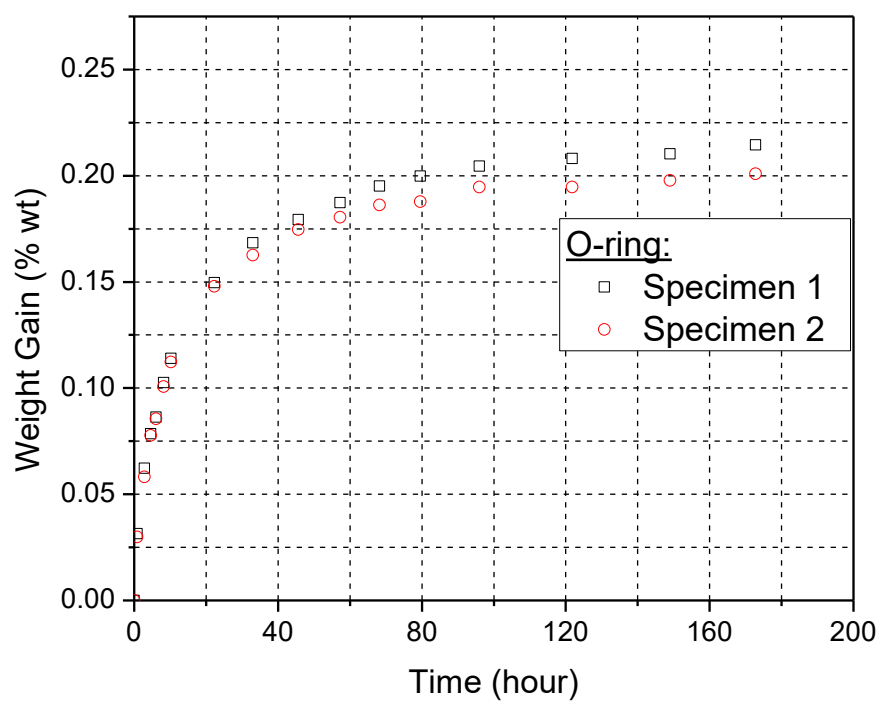

(d)

Figure 8 Moisture absorption of the three specimens: (a), (b), and (c), and O-rings (d) at the moisture condition of $45^{\circ} \mathrm{C} / 85 \% \mathrm{RH}$

Table 3 Dimensions of the specimens tested at $45{ }^{\circ} \mathrm{C} / 85 \% \mathrm{RH}$ along with the experimentally determined hygroscopic material properties

\begin{tabular}{|c|c|c|c|}
\hline \multirow{2}{*}{ Material } & \multirow{2}{*}{$\begin{array}{c}\text { Dimension } \\
(\mathrm{mm} \times \mathbf{m m} \times \mathbf{m m})\end{array}$} & \multicolumn{2}{|c|}{$45{ }^{\circ} \mathrm{C} / 85 \%$ RH Test } \\
\hline & & $D\left(\mathrm{~mm}^{2} / \mathrm{sec}\right)$ & $\mathrm{C}_{\text {sat }}(\% w t)$ \\
\hline A & $30 \times 30 \times 1$ & $5.70 \mathrm{E}-7$ & 3.25 \\
\hline $\mathrm{B}$ & $30 \times 30 \times 2$ & $3.25 \mathrm{E}-6$ & 0.28 \\
\hline $\mathrm{C}$ & $30 \times 30 \times 1.5$ & $1.56 \mathrm{E}-6$ & 0.36 \\
\hline O-ring & ID: $23 \mathrm{~mm} \mid \mathrm{CS}: 3.5 \mathrm{~mm}$ & $5.74 \mathrm{E}-5$ & 0.21 \\
\hline
\end{tabular}




\subsection{Hygroscopic Material Property Calculations}

To obtain the diffusivity and solubility of each material, the weight gain during absorption between the two specimens for each material at a particular condition were first averaged. The experimental results are shown in Figure 9 for the three materials. Each figure represents the moisture absorption curves for one particular material at the three tested conditions.

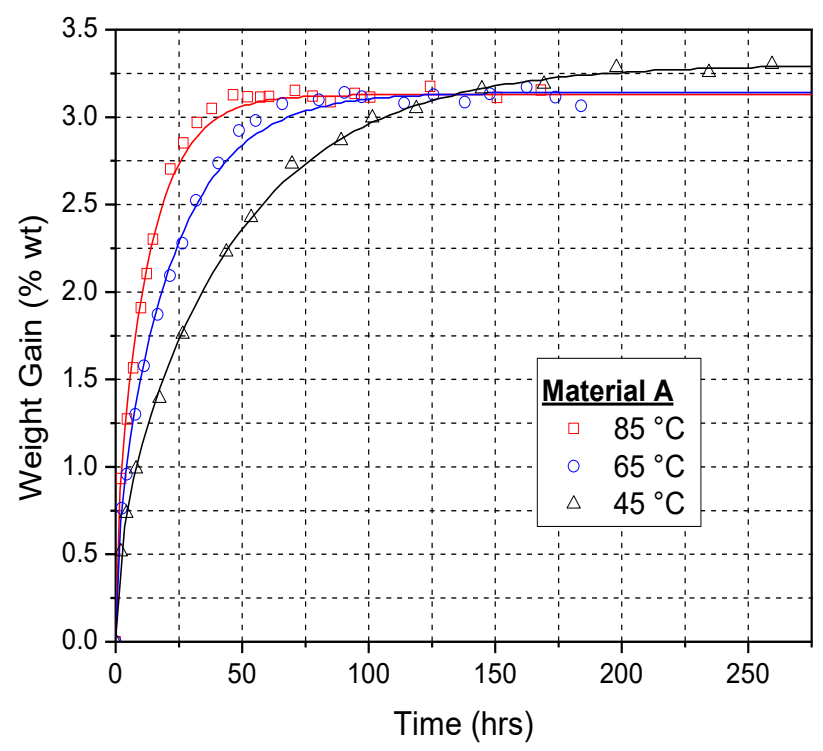

(a) 


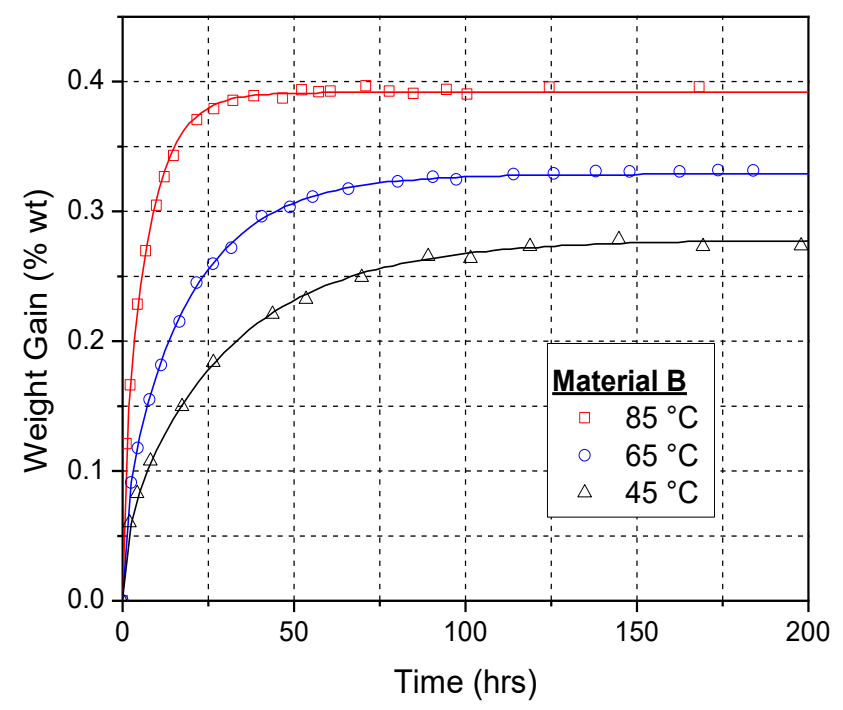

(b)

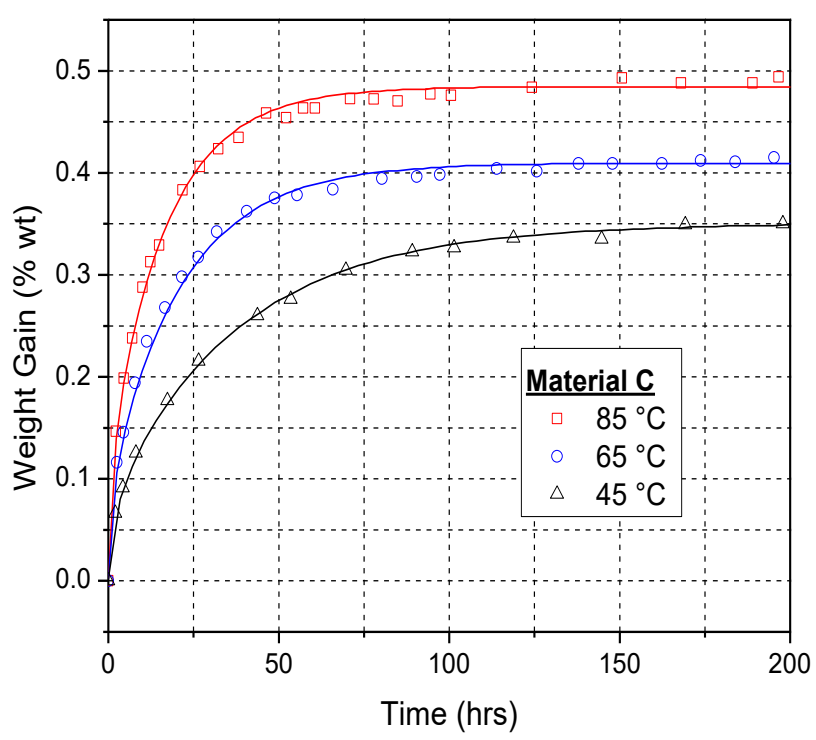

(c)

Figure 9 Moisture weight gain histories of three different composite polymers, each subjected to $85 \% \mathrm{RH}$ at $85^{\circ} \mathrm{C}, 65^{\circ} \mathrm{C}$, and $45^{\circ} \mathrm{C}$, respectively. The data 
points and solid lines represent the measurement data and Fickian

predictions, respectively.

Equation (25) was used to calculate the saturated concentrations of each material. A summary table containing the saturated concentrations of each material and the O-rings is shown in Table 4. Solubility can then be determined from Henry's law (11).

Table 4 Saturated concentrations

\begin{tabular}{|c|c|c|c|}
\hline \multirow{2}{*}{ Material } & \multicolumn{3}{|c|}{ Experimental Results } \\
\cline { 2 - 4 } & $85{ }^{\circ} \mathrm{C} / 85 \% \mathrm{RH}$ & $65^{\circ} \mathrm{C} / 85 \% \mathrm{RH}$ & $45^{\circ} \mathrm{C} / 85 \% \mathrm{RH}$ \\
\cline { 2 - 4 } & $\mathbf{C}_{\text {sat }}(\mathbf{\%} \mathbf{w t})$ & $\mathbf{C}_{\text {sat }}(\boldsymbol{\%} \mathbf{w t})$ & $\mathbf{C}_{\text {sat }}(\boldsymbol{\%} \mathbf{w t})$ \\
\hline $\mathrm{A}$ & 3.13 & 3.12 & 3.25 \\
\hline $\mathrm{B}$ & 0.39 & 0.33 & 0.28 \\
\hline $\mathrm{C}$ & 0.49 & 0.41 & 0.36 \\
\hline O-ring & 0.30 & 0.24 & 0.21 \\
\hline
\end{tabular}

At this point, we can recall the three thermal-moisture analogies described in section 2 of this report. The fundamental principle of the advanced analogy depended on the situation where $C_{s a t}$ is not a function of temperature. To visually see this 
relationship between $C_{\text {sat }}$ and temperature for the three materials, the data in Table 4 was graphed below.

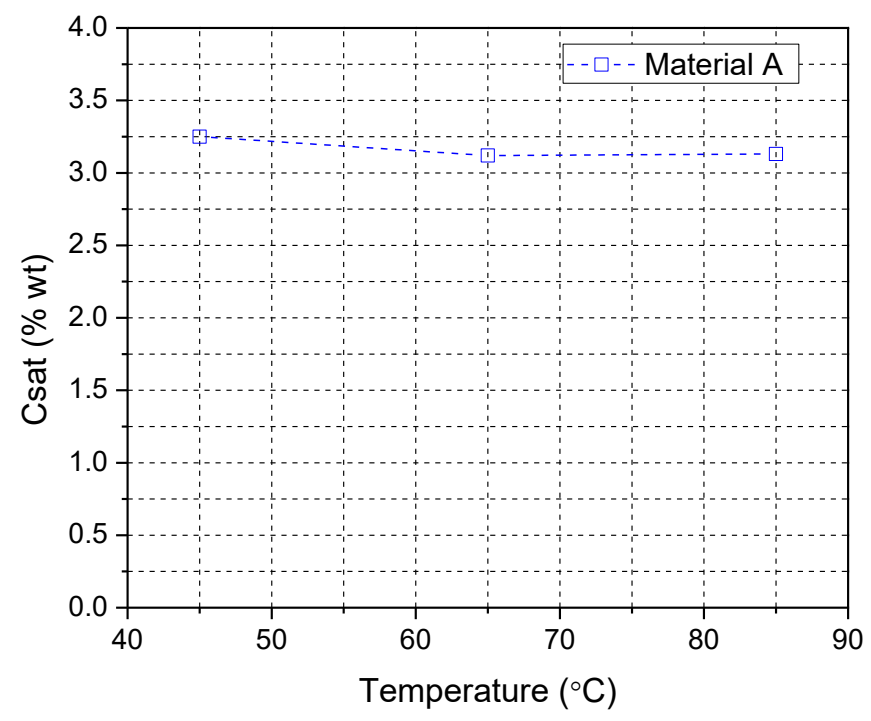

(a)

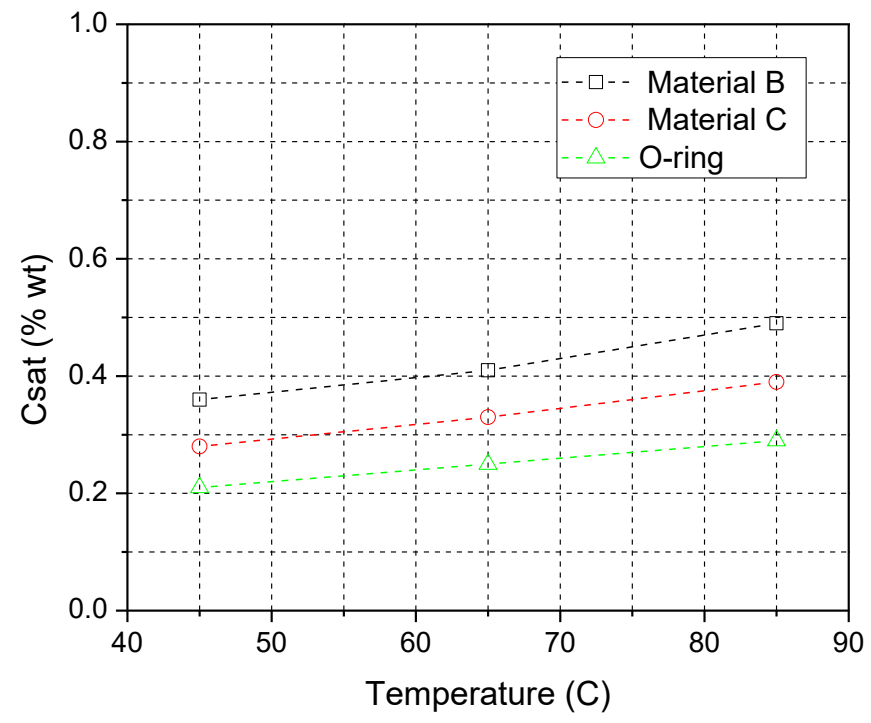

(b) 
Figure 10 Saturated concentration as a function of temperature for material A plotted in (a) and materials B and C plotted in (b).

Material A did not exhibit temperature dependent saturated concentration behavior, but materials B, C, and O-ring did; their saturated concentrations increased as temperature increased. Therefore, for the latter two materials, the advanced analogy cannot be used. More details on the analogy used will be discussed in the modeling methodology section.

The diffusivity was calculated inversely from the moisture weight gain data at each temperature condition by using the closed form solution for a 3D block specimen with all outside surfaces subject to a humid environment [33]

$$
\begin{aligned}
& \frac{m(t)}{m_{\text {sat }}}=1-\frac{512}{\pi^{6}} \sum_{l=0}^{\infty} \sum_{m=0}^{\infty} \sum_{n=0}^{\infty} \frac{e^{\left(\frac{-D t}{L_{\text {eqv }}^{2}}\right)}}{(2 l+1)^{2}(2 m+1)^{2}(2 n+1)^{2}} \\
& L_{\text {eqv }}^{2}=\left\{\left[\frac{(2 l+1) \pi}{x_{0}}\right]^{2}+\left[\frac{(2 m+1) \pi}{y_{0}}\right]^{2}+\left[\frac{(2 n+1) \pi}{z_{0}}\right]^{2}\right\}^{-1}
\end{aligned}
$$

where $x_{0}, y_{0}$, and $z_{0}$ are the dimensions of the block in each direction. This equation has been widely used to determine the diffusivity of block-shaped polymer specimens from moisture weight gain experiments. A MATLAB script was used to solve the equation. The Fickian curves obtained from the equation for each material at a given temperature are plotted as lines in Figure 9. They follow the experimental data well, confirming that the materials follow the ideal Fickian behavior.

To determine the diffusivity of the O-rings, commercially available FEA software (ANSYS) was used. The O-rings were modeled as 2D axisymmetric circles, with the moisture loading applied on the circumference. The O-rings were initially 
assumed to be fully dried. The resulting moisture absorption curves from the numerical simulation were then compared to the experimental data, and numerous runs were made changing the O-ring diffusivity on each run to fit the prediction to the data. More details about numerical modeling methodology will be discussed in the following section. Nevertheless, through this iterative technique, a reasonable estimate for the diffusivity of the O-rings were calculated at the three loading conditions.

The Arrhenius relations for diffusivity and solubility can be transformed as:

$$
\ln D=\ln \left(D_{0}\right)-\left(\frac{E_{D}}{R}\right) \frac{1}{T} \quad \text { and } \ln S=\ln \left(S_{0}\right)-\left(\frac{E_{S}}{R}\right) \frac{1}{T}
$$

Then, a linear regression was utilized to determine the diffusivity coefficient and the activation energy of diffusivity, and similarly the solubility coefficient and the activation energy of solubility.

The moisture absorption data is plotted using the above equations for diffusivity and solubility in Figure 11 and Figure 12, respectively. For the diffusivity data, the slope $E_{D} / R$ represents the activation energy of diffusivity of each material, scaled by a factor or $1 / R$. From the $y$-intercept $\ln \left(D_{0}\right)$, the diffusivity coefficient can be determined for each material. In a similar way, the activation energy of solubility and solubility constant can be determined. 


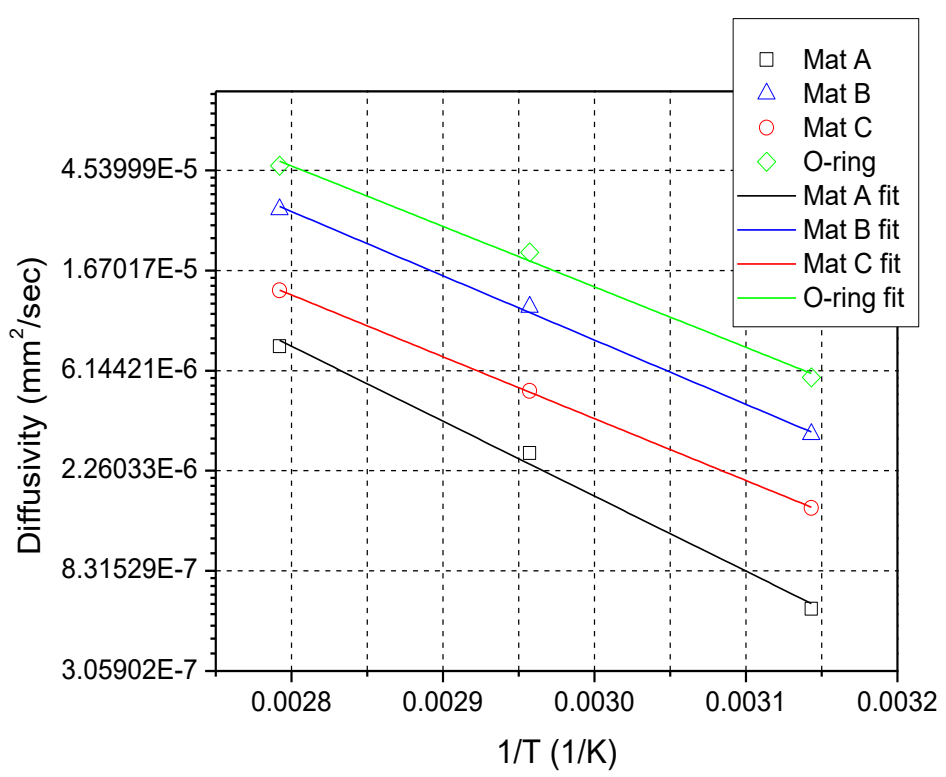

Figure 11 Temperature dependent moisture diffusivity

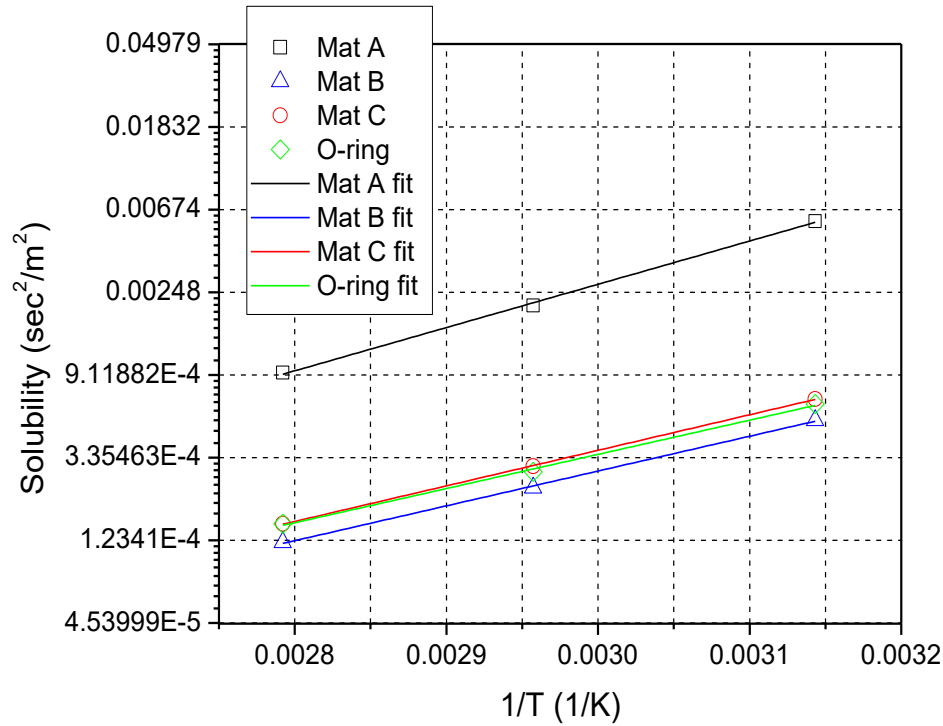

Figure 12 Temperature dependent moisture solubility

From the line of best fit, $D$ and $S$ can be interpolated, allowing for material properties at different temperatures to be known, which is essential for the predictive capability. $D$ and $S$ are calculated from three different temperatures (rather than two) 
to ensure an accurate predictive capability of hygroscopic material properties. Table 5 and Table 6 summarize the calculated hygroscopic properties of the materials at given environmental conditions.

Table 5 Diffusivity

\begin{tabular}{|c|c|c|c|c|c|}
\hline \multirow{2}{*}{ Material } & \multicolumn{3}{|c|}{ Diffusivity $D\left(\mathrm{~mm}^{2} / \mathrm{sec}\right)$} & \multirow{2}{*}{$\begin{array}{c}D_{0} \\
\left(\mathrm{~mm}^{2} / \mathrm{sec}\right)\end{array}$} & \multirow{2}{*}{$\begin{array}{c}\text { ED } \\
(\mathrm{J} / \mathrm{mol})\end{array}$} \\
\hline & $85^{\circ} \mathrm{C} / 85 \% \mathrm{RH}$ & $65^{\circ} \mathrm{C} / 85 \% \mathrm{RH}$ & $45^{\circ} \mathrm{C} / 85 \% \mathrm{RH}$ & & \\
\hline A & $7.84 \mathrm{E}-6$ & $2.70 \mathrm{E}-6$ & $5.70 \mathrm{E}-7$ & 9940 & 62239 \\
\hline B & $3.08 \mathrm{E}-5$ & $1.16 \mathrm{E}-5$ & $3.25 \mathrm{E}-6$ & 1922 & 53364 \\
\hline $\mathrm{C}$ & $1.37 \mathrm{E}-5$ & $5.02 \mathrm{E}-6$ & $1.56 \mathrm{E}-6$ & 426 & 51365 \\
\hline O-ring & $5.18 \mathrm{E}-5$ & $2.00 \mathrm{E}-5$ & $5.74 \mathrm{E}-6$ & 2267 & 52311 \\
\hline
\end{tabular}

Table 6 Solubility

\begin{tabular}{|c|c|c|c|c|c|}
\hline \multirow{2}{*}{ Material } & \multicolumn{3}{|c|}{ Solubility $S\left(\sec ^{2} / \mathrm{m}^{2}\right)$} & \multirow{2}{*}{$\begin{array}{c}S_{0} \\
\left(\sec ^{2} / \mathbf{m}^{2}\right)\end{array}$} & \multirow{2}{*}{$\begin{array}{c}\mathrm{Es}_{\mathrm{S}} \\
(\mathrm{J} / \mathrm{mol})\end{array}$} \\
\hline & $85^{\circ} \mathrm{C} / 85 \% \mathrm{RH}$ & $65^{\circ} \mathrm{C} / 85 \% \mathrm{RH}$ & $45^{\circ} \mathrm{C} / 85 \% \mathrm{RH}$ & & \\
\hline $\mathrm{A}$ & $9.36 \mathrm{E}-4$ & $2.11 \mathrm{E}-3$ & $5.87 \mathrm{E}-3$ & 4.14E-10 & -43514 \\
\hline B & $1.20 \mathrm{E}-4$ & $2.33 \mathrm{E}-4$ & $5.27 \mathrm{E}-4$ & 9.28E-10 & -35016 \\
\hline $\mathrm{C}$ & $1.50 \mathrm{E}-4$ & $3.02 \mathrm{E}-4$ & $6.81 \mathrm{E}-4$ & 9.09E-10 & -35768 \\
\hline O-ring & $1.51 \mathrm{E}-4$ & $2.82 \mathrm{E}-4$ & $6.42 \mathrm{E}-4$ & 1.42E-9 & -34374 \\
\hline
\end{tabular}




\section{Chapter 4: Modeling Methodology and Experimental Validation}

The methodology of the numerical prediction of moisture transport is described first. Then, this methodology is validated using a unique experimental setup.

\subsection{Numerical Modeling Methodology}

A numerical model using commercially available finite element analysis (FEA) software, ANSYS, was developed to predict the transient moisture transport. This model utilizes the well-established analogy between heat transfer and mass transfer (see Table 7). The temperature-equivalent field variable for transient moisture transport is the moisture concentration $C$ normalized by solubility $S$ (normalized analogy), which is continuous across the interface of two dissimilar materials. Its unit is "Pascal" and it is used instead of temperature in the transient thermal model in ANSYS. The normalized analogy was used to relate moisture transport to thermal diffusion because this is a multimaterial problem (direct analogy not valid) where the saturated moisture concentration is not a linear function to relative humidity (advanced analogy not valid) for all of the materials in this study, as the experimental data showed in the previous section.

Table 7 Analogy between heat transfer and moisture diffusion [19]

\begin{tabular}{|c|c|c|}
\hline & Heat Transfer & Moisture Transfer \\
\hline Field Variable & Temperature, $T$ & Pressure, $p_{V}$ \\
\hline Density & $\rho$ & 1 \\
\hline Conductivity & $k$ & $P=D S$ \\
\hline Specific heat & $c_{p}$ & $S$ \\
\hline
\end{tabular}


The boundary condition at the housing material and the cavity interface (see Figure 1) is transient. The cavity vapor pressure increment at each time step should be calculated and subsequently used to update the boundary condition at the inner surface after each step. This updating procedure requires a user-defined algorithm. The effective volume scheme was adopted to cope with the challenge [20].

The scheme models the internal cavity as an imaginary polymer with an extremely large diffusivity and an "equivalent solubility." The large diffusivity (several orders higher than that of the housing materials) ensures that the gas pressure is uniform within the cavity. The solubility of the effective volume cannot be chosen arbitrarily; instead, the effective solubility should be derived from the gas law and Henry's law as

$$
S_{c}=\frac{C}{p}=\frac{\rho}{n R T / V}=\frac{M_{w}}{R T}
$$

where $\rho, V$, and $n$ are the water vapor density $\left(\mathrm{kg} \mathrm{m}^{-3}\right)$, the volume $\left(\mathrm{m}^{3}\right)$ of the cavity, and the number of moles (mol). The moisture concentration inside the fictitious polymer can be represented by the water vapor density. By implementing the effective volume scheme, the transient boundary condition transforms into a fixed boundary condition, simplifying the problem by not requiring a user-defined algorithm.

\subsection{Experimental Validation of Modeling Methodology}

The experimental setup is introduced first. Then, the numerical model is described. Lastly, the numerical predictions are compared to the experimental results. 


\subsubsection{Experimental Setup}

To assess the validity of utilizing the thermal moisture analogy with a pseudomaterial to predict the moisture transport through a composite polymer, a unique experimental setup was fabricated in which the in-situ humidity condition of a cavity enclosed by a housing material could be measured. A simplified schematic of the experimental setup is shown in Figure 13.

$$
\text { Ambient environment - }\left(R h_{a}, T_{a}\right)
$$

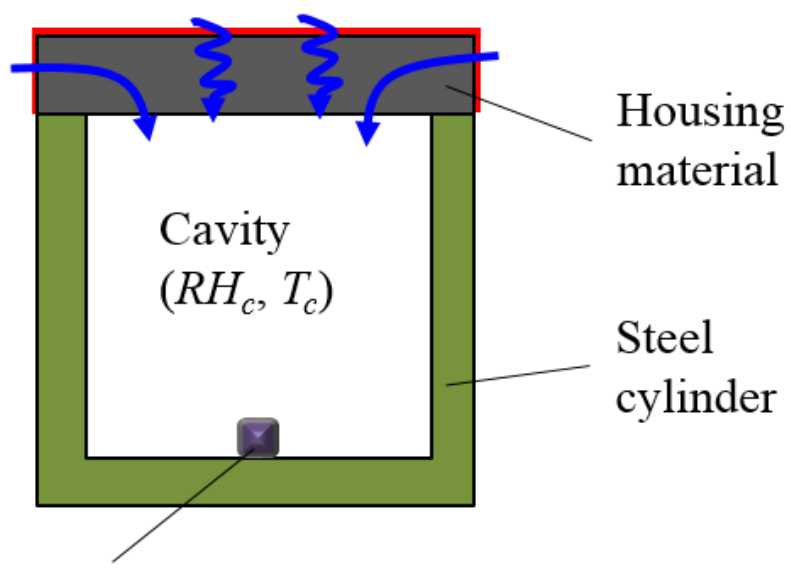

\section{Environmental sensor}

Figure 13 Simplified schematic of bulk moisture transport through the housing into the cavity. 


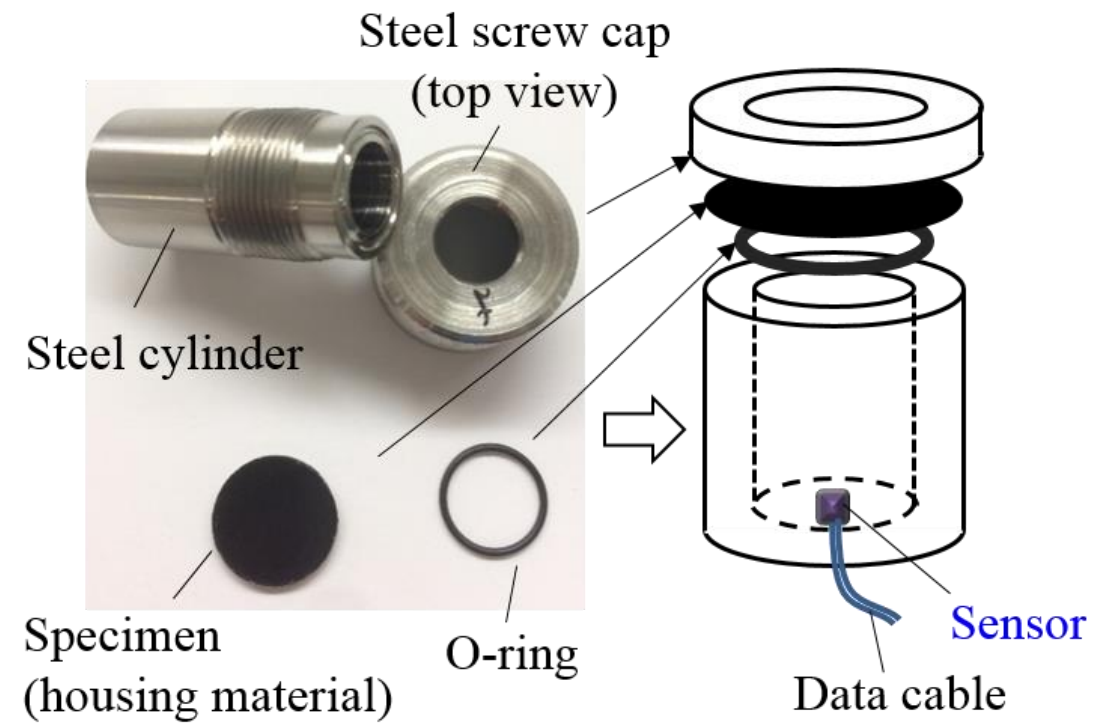

(a)

(b)

Figure 14 (a) Picture of disassembled steel sensors and (b) exploded view of experimental sensor set-up. The sensor is located at the bottom of the cavity inside the steel cylinder and is connected to a data collection box through a wire.

As shown in Figure 14(b), the setup consisted of a stainless steel enclosure with a top cover made of three different disk-shaped composite polymers, each of thickness $1 \mathrm{~mm}$ and diameter $16 \mathrm{~mm}$, enclosing a $2.4 \mathrm{~cm}^{3}$ cavity. An environmental sensor capable of recording the in-situ temperature, air pressure, and relative humidity as a function of time was placed at the bottom of the test apparatus. To minimize variability in the setup, the cavity was sealed by an O-ring. The O-ring seal was fabricated such that moisture transport through it was consistent. This assumption was validated through a supplementary experiment using an impermeable material (e.g., aluminum) instead of a composite polymer for the disk material. 
The O-ring and the composite disks were initially baked at $75{ }^{\circ} \mathrm{C}$ (at approximately $1 \% \mathrm{RH}$ ) and weighed with a high precision balance until the weight remained unchanged for an extended period of time. The disk, O-ring, and sensor setup were then assembled at room condition. To minimize uncertainties, the assembled setup was further baked at $75{ }^{\circ} \mathrm{C}$ until the cavity reached steady state moisture concentration. Then, the assemblies were subjected to a test condition (e.g., $75{ }^{\circ} \mathrm{C} / 75 \% \mathrm{RH}$ ) inside an environmental chamber (ESPEC SH-241), and the moisture content inside the cavity was recorded as a function of time. This experiment was replicated such that two independent data sets were obtained for each material. The experimental results are shown as discrete data points in Figure 15 for materials A, B, and $\mathrm{C}$.

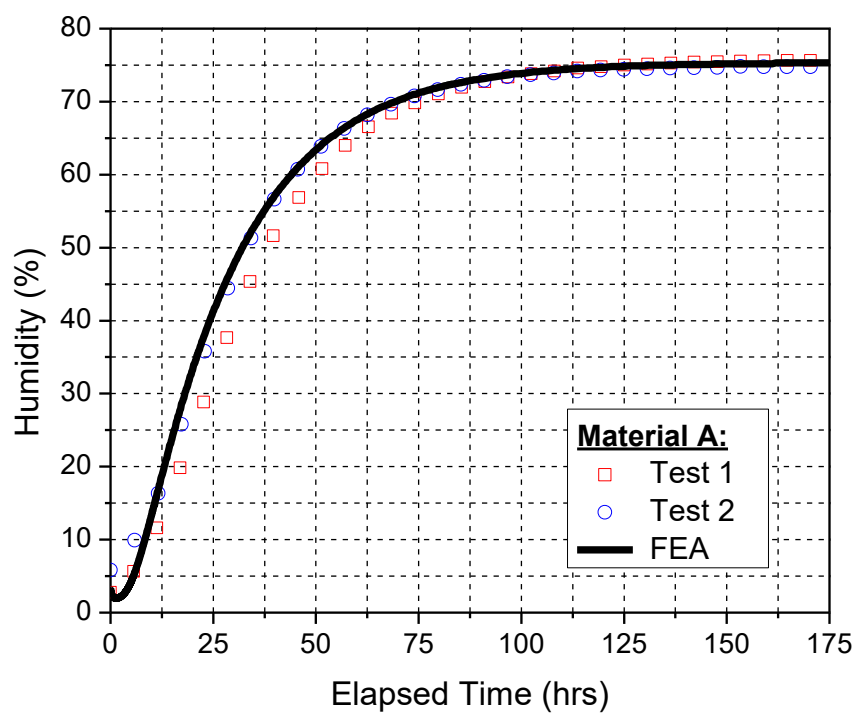

(a) 


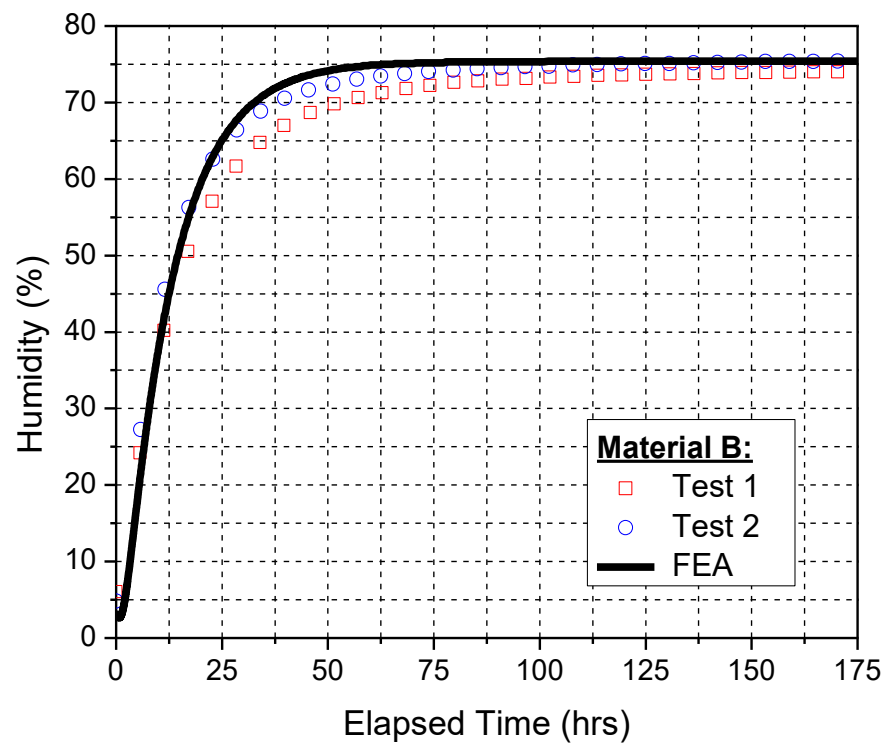

(b)

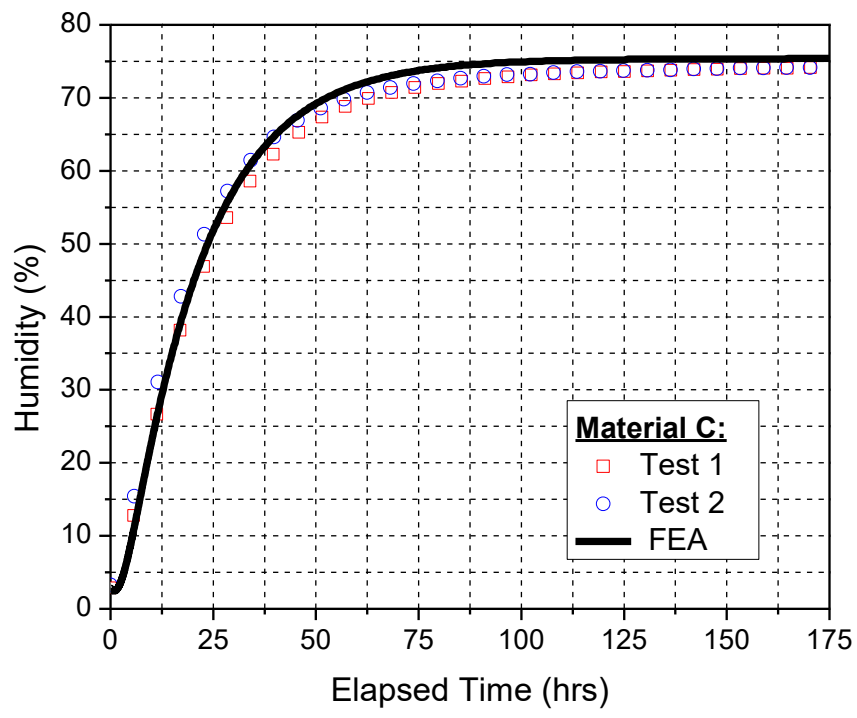

(c)

Figure 15 Comparisons between experimental data (discrete data points) and associated numerical predictions (solid line) for: (a) material A, (b) material 
$\mathrm{B}$, and (c) material C, obtained from two independent sensor tests at $75^{\circ} \mathrm{C} / 75 \% \mathrm{RH}$.

\subsubsection{Numerical Prediction of Permeation and Comparison to Experimental Data}

The modeling approach described in the numerical modeling methodology section was applied to this specific experimental setup. The effective volume scheme was used in conjunction with the thermal-moisture analogy to numerically predict the moisture transport through the composite polymer and into the cavity as a function of time. The model has three main components: a housing material (specimen), a cavity, and an O-ring. The hygroscopic material properties of the disks and O-rings were interpolated at $75{ }^{\circ} \mathrm{C} / 75 \% \mathrm{RH}$ using the Arrhenius relation in equation (13) and are shown in Table 8, along with the material properties of the cavity. The cavity was treated as an imaginary material with a very large diffusivity and an equivalent solubility using equation (28).

Table 8 Predicted moisture properties at $75{ }^{\circ} \mathrm{C}$

\begin{tabular}{|c|c|c|c|}
\hline Material & $\boldsymbol{D}\left(\mathbf{m}^{2} / \mathbf{s e c}\right)$ & $\boldsymbol{S}\left(\mathbf{s e c}^{2} / \mathbf{m}^{2}\right)$ & $\boldsymbol{P}(\mathbf{s e c})$ \\
\hline A & $4.51 \mathrm{E}-12$ & $1.41 \mathrm{E}-3$ & $6.36 \mathrm{E}-15$ \\
\hline B & $1.88 \mathrm{E}-11$ & $1.67 \mathrm{E}-4$ & $3.14 \mathrm{E}-15$ \\
\hline C & $8.30 \mathrm{E}-12$ & $2.13 \mathrm{E}-04$ & $1.77 \mathrm{E}-15$ \\
\hline O-ring & $3.18 \mathrm{E}-11$ & $2.05 \mathrm{E}-4$ & $6.53 \mathrm{E}-15$ \\
\hline Cavity & 1 & $6.22 \mathrm{E}-6$ & $6.22 \mathrm{E}-6$ \\
\hline
\end{tabular}


Because the experimental setup is cylindrical and diffusion is symmetric with respect to the axis of rotation, the model can be simplified without loss of generality into a 2D axisymmetric model. Although simplified, the axisymmetric model effectively represents the permeation behavior of moisture through the actual polymer structure. The resulting numerical model is shown in Figure 16. The only surface through which moisture can permeate is the outer surface of the housing material up until the O-ring curve (shown as a bolded red line in Figure 16). All other surfaces are impervious to moisture $\left(\nabla p_{v}=0\right)$. 


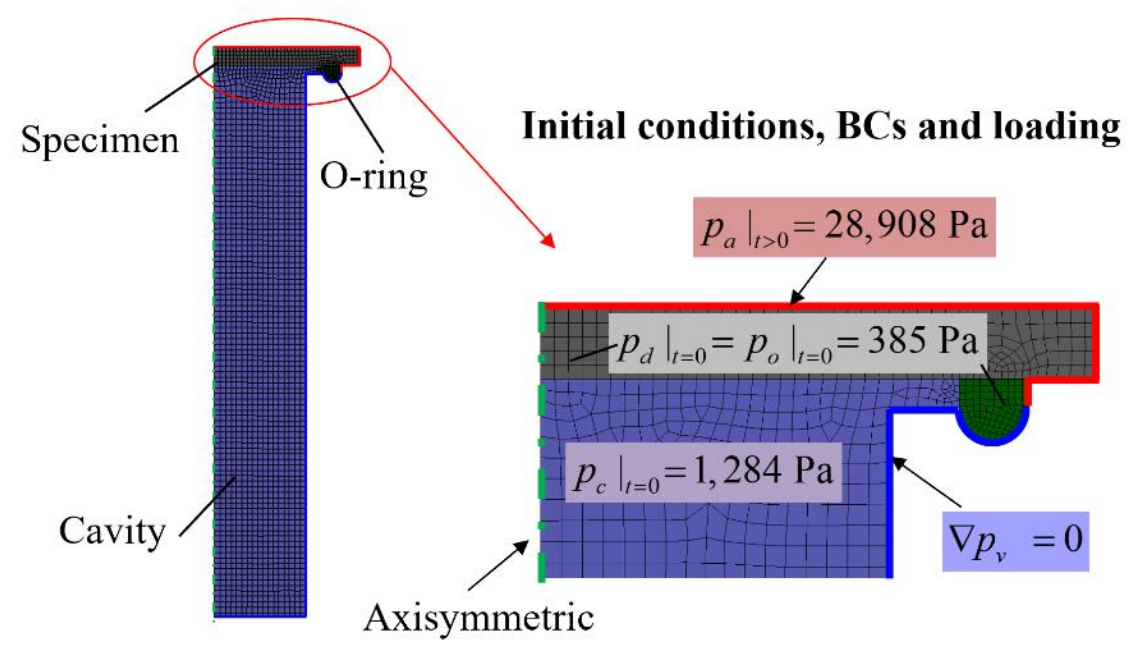

Figure 16 2-D axisymmetric (about the leftmost edge) model with initial conditions, boundary conditions, and loading at $75{ }^{\circ} \mathrm{C} / 75 \% \mathrm{RH}$.

For the transient thermal analysis in ANSYS, the loading and initial conditions were converted from temperatures into normalized field variables with units of pressure using equation (12). The disk and O-ring were in steady state at $75^{\circ} \mathrm{C} / 1 \% \mathrm{RH}$ before entering the humidity chamber. This humidity condition corresponds to an initial condition of $385 \mathrm{~Pa}$ for the numerical simulation. The moisture loading of $75^{\circ} \mathrm{C} / 75 \% \mathrm{RH}$ corresponds to $28,908 \mathrm{~Pa}$ after using equation (12).

Moving the sensors from the baking chamber into the humidity chamber resulted in a small temperature drop of $2-3{ }^{\circ} \mathrm{C}$ (as the assembled sensors were subject to room condition for a few minutes). Because the sensor was below $75^{\circ} \mathrm{C}$ for only a few minutes, moisture permeation through the housing was negligible. Additionally, because the thermal moisture analogy is only valid for uniform and time-independent temperature fields, the ideal gas law was used to convert the moisture condition back to $75^{\circ} \mathrm{C}$, assuming fixed mass and volume of moisture inside the cavity. To confirm 
the accuracy of this assumption, the resulting moisture condition was calculated using equation (12) for the two cases: after using the ideal gas law, and once the sensor reached $75^{\circ} \mathrm{C}$. The difference between the two methods was less than $0.5 \%$, validating the use of the ideal gas law. The initial condition of the cavity was then converted from temperature and relative humidity to its associated value in units of pressure.

The initial condition of the cavity, disk, and O-ring for the three materials is shown in Table 9. Recall from Figure 15 that two sets of independent experimental data were recorded for each material. It is worth noting that the initial conditions of the cavity varied slightly between these two tests for each material, but this difference had negligible effect on the numerical prediction. For simplicity, only one prediction will be shown for each material.

Table 9 Initial conditions used in numerical model of the sensor experiment

\begin{tabular}{|c|c|}
\hline Material & Initial Condition (Pa) \\
\hline Cavity of Material A & 1077 \\
\hline Cavity of Material B & 1247 \\
\hline Cavity of Material C & 1111 \\
\hline O-ring \& Disk & 385 \\
\hline
\end{tabular}

The numerical prediction contained varying mesh element sizes for each material, with the finest mesh of $0.1 \mathrm{~mm}$ for the O-ring, $0.2 \mathrm{~mm}$ for the disk, and 0.3 $\mathrm{mm}$ for the cavity. A total of 6520 nodes were used. A mesh 5 times finer was used and yielded identical results, indicating that the current mesh was satisfactory. To accurately capture the transient behavior of the moisture permeation through the 
composite polymer, 16 user-defined time steps were used, spaced out by a factor of two such that more calculations were completed during the transient portion of moisture permeation. The temperature of the cavity (corresponding to pressure) was the desired solution, and using equation (12) the relative humidity was calculated as a function of time. It is important to note that due to the very large equivalent diffusivity of the pseudo-material, the cavity has a uniform moisture content throughout the body (which is expected of a gas in such a small volume). An arbitrary point in the cavity was chosen to measure the moisture condition inside the cavity as a function of time. This prediction for each material is plotted against the associated experimental data in Figure 15. The predictions and experimental data for the three materials agree well with each other, which corroborates the validity of the modeling approach and the measured material properties. The numerical prediction for material B slightly overestimates the moisture permeation through the housing for both tests. A possible explanation for this variation is an overestimate of the diffusivity of material $\mathrm{B}$, as the diffusivity is interpolated from moisture weight gain experiments. Any small variation in the material property measurements can lead to large differences in interpolated values due to the exponential form of the Arrhenius equation (13). In general, the experimental data follow the prediction provided by the numerical solution, thereby validating the modeling methodology. 


\section{Chapter 5: Implementation of the Proposed Methodology}

The proposed methodology is implemented in the accelerated testing of a general configuration of automotive enclosures. The results from the model are then presented for a typical housing thickness of $1 \mathrm{~mm}$ and various materials.

\subsection{Typical Enclosures for Automotive Electronics}

Humidity-sensitive automotive electronics, such as airbag sensors (acceleration and pressure sensors) and yaw-rate sensors for $\mathrm{ESP}^{\circledR}$ systems, are typically protected by composite polymers, through which moisture transport occurs. Housing materials are often made from polybutylene terephthalate (PBT) materials, which are characterized by high dimensional stability and stiffness, as well as good heat resistance. The material properties can be tailored to specific applications by adding fillers, reinforcing materials, and additives during compounding, optimizing the properties of the housings for each application [34]. These polymer housings are typically sealed with an assembly method such as bolting with an O-ring, adhesion, laser weld, hot plate, or linear welding $[35,36]$.

The dimensions of the housing depend on the type of electronics enclosed; typically, the cavity has a volume around $1.5 \mathrm{~cm}^{3}$ to $100 \mathrm{~cm}^{3}$ with a wall thickness of $1.0-1.5 \mathrm{~mm}$. The quantity and mounting locations of these enclosures strongly depends on the car. Acceleration sensors, for example, are often fixed behind bumpers and on the B-pillar of the chassis to detect mechanical shocks caused by accidents. Other sensors protected by these housings can be found mainly inside the doors or in the passenger compartment. 


\subsection{Numerical Prediction of Moisture Transport for Automotive Electronics Enclosures}

The enclosure (illustrated in Figure 1 as the housing material) was modeled as a homogenous hollow box. The housing thickness and cavity volume were chosen to be $1 \mathrm{~mm}$ approximately $47 \mathrm{~cm}^{3}$, respectively, as both values are within the ranges of common automotive enclosure designs. As mentioned earlier, in the field application, the near environment (ambient) varies based on the car, mounting location, and outside environment. For the purpose of this study, common accelerated testing standards (i.e. AEC-Q100 performed according to JESD22-A101) were used. In this standard, equipment is subjected to an accelerated test environment of $85{ }^{\circ} \mathrm{C} / 85 \% \mathrm{RH}$ for 1000 hours, applied on the exterior surfaces of the housing at time $\mathrm{t}>0$.

The model utilizing the thermal-moisture analogy and fictitious polymer is shown in Figure 17, along with the initial conditions and boundary conditions. Initially, the housing material and cavity were assumed to be fully dried (0 Pa) and at room condition $23{ }^{\circ} \mathrm{C} / 50 \% \mathrm{RH}(1404 \mathrm{~Pa})$, respectively, using equation (12) to convert the humidity conditions to normalized field variables. The humidity loading of 85 ${ }^{\circ} \mathrm{C} / 85 \% \mathrm{RH}$ was likewise converted using the thermal moisture analogy. The numerical

predictions of this analysis for materials A, B, and C are shown Figure 18. All three materials saturate well before 1000hrs. 


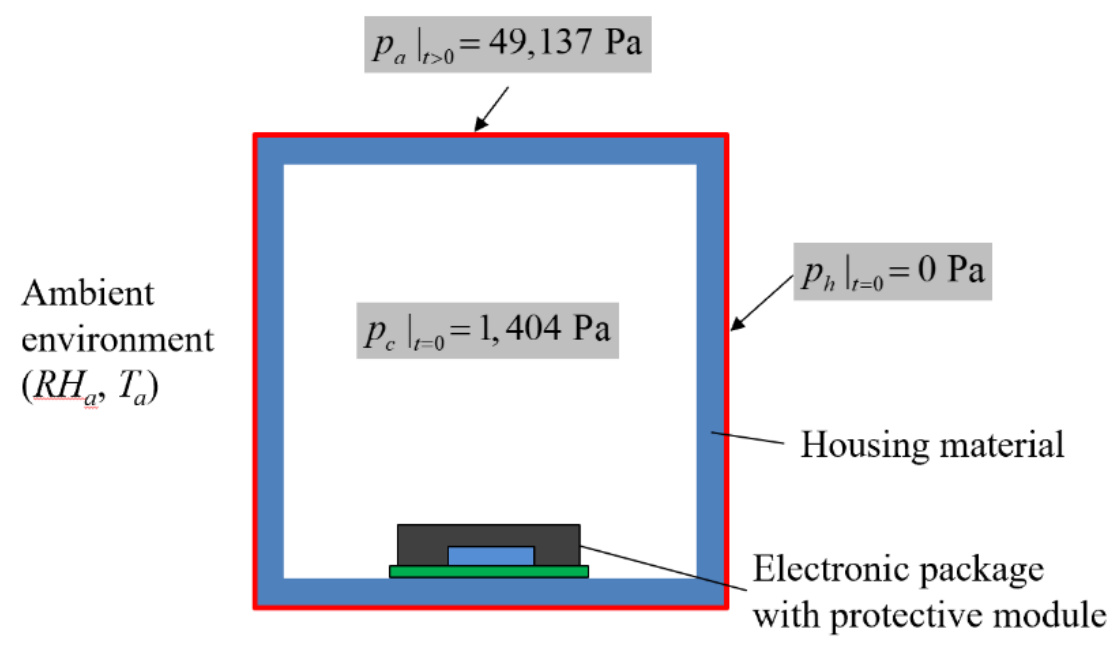

Figure 17 Cross-sectional view of the 3D box model with initial conditions, boundary conditions and loading. 1,404 $\mathrm{Pa}, 0 \mathrm{~Pa}$, and 49,137 $\mathrm{Pa}$ represent the initial conditions of the cavity (room condition $23{ }^{\circ} \mathrm{C} / 50 \% \mathrm{RH}$ ), the housing completely dried (0 Pa), and boundary condition of the ambient $\left(85^{\circ} \mathrm{C} / 85 \% \mathrm{RH}\right)$. 


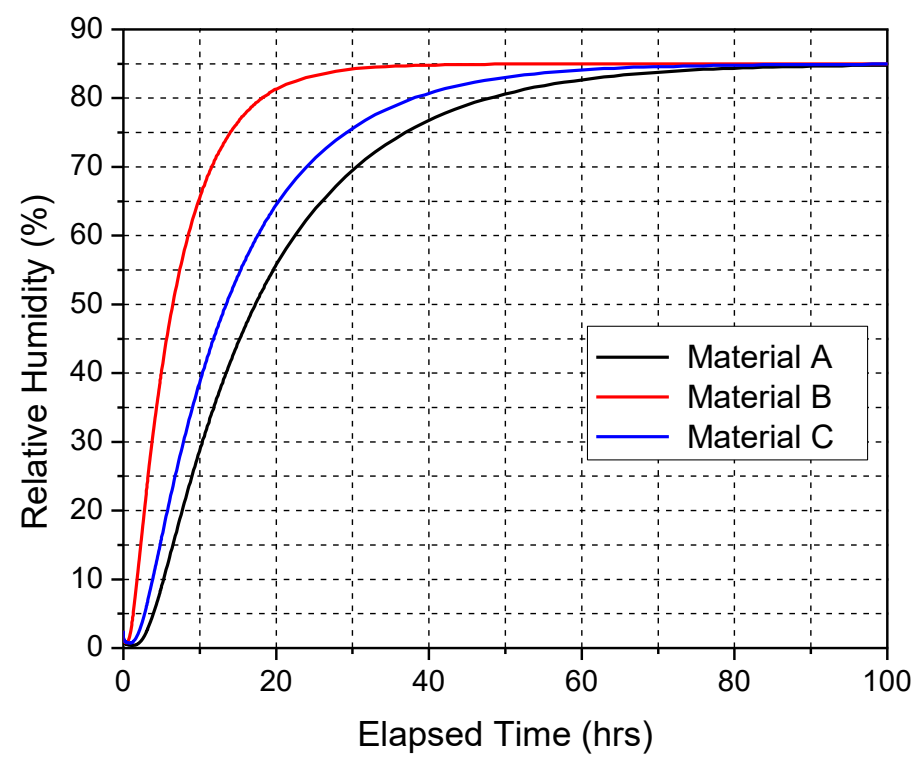

Figure 18 Numerical prediction of moisture transport through a general automotive electronics enclosure composed of material A, B, and C, subjected to accelerated testing at $85{ }^{\circ} \mathrm{C} / 85 \mathrm{RH}$.

This modeling methodology was also applied to estimate the moisture transport through the housing into the cavity containing humidity-sensitive electronics for automobiles subject to real world harsh environmental conditions. Two environmental conditions were chosen for this case study: both very hot environments, one with high humidity another with low humidity. The hot and humid environment is taken to be $28.3{ }^{\circ} \mathrm{C} 83.5 \% \mathrm{RH}(3230 \mathrm{~Pa})$, which is the average climate condition in Singapore during May, while $38.3{ }^{\circ} \mathrm{C} 14 \% \mathrm{RH}(948 \mathrm{~Pa}$ ) represents the hot and dry climate, which is the average climate condition in Kuwait City, Kuwait during July [37, 38]. As before, the housing material and cavity were assumed to be fully dried ( $0 \mathrm{~Pa})$ and at room 
condition $23{ }^{\circ} \mathrm{C} / 50 \% \mathrm{RH}(1404 \mathrm{~Pa})$, respectively. The resulting predictions can be seen in Figure 19 below.

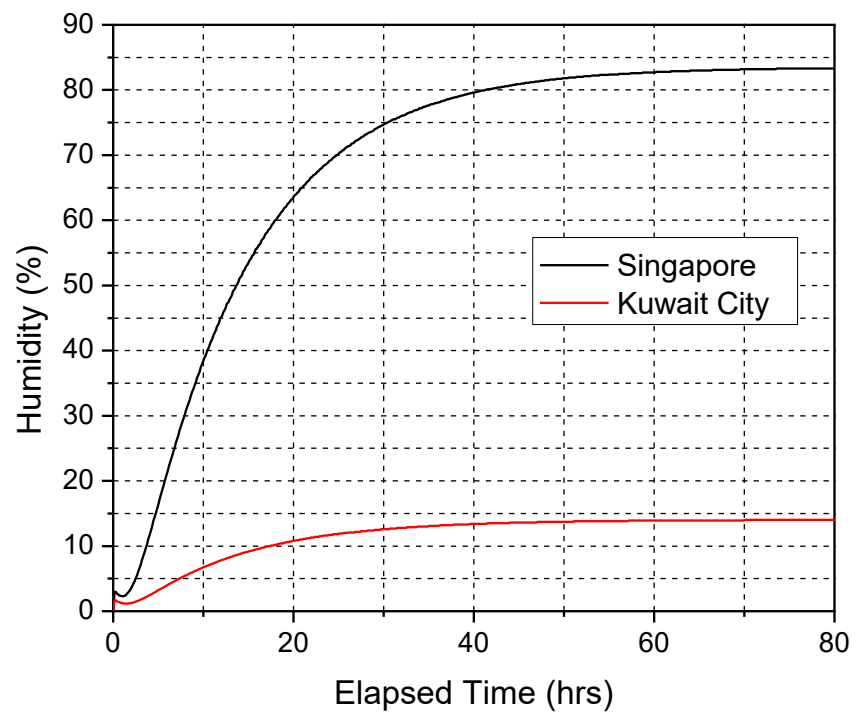

Figure 19 Prediction of moisture transport through 3D box model under real-world moisture conditions

It is anticipated that this capability can be used to guide accelerated moisture testing of housings and to help predict moisture transport through housings depending on operating conditions, materials, and/or designs. 


\title{
Chapter 6: Conclusion
}

\author{
A predictive capability of moisture transport through housing materials \\ enclosing humidity-sensitive electronics was developed. The prediction was \\ implemented using ANSYS and the results were validated experimentally through a \\ setup fabricated to measure the in-situ temperature and relative humidity as a function \\ of time inside a cavity enclosed by housing materials. The model enables a preventive \\ description of humidity-dependent behavior of the module by providing insight into the \\ humidity condition on the surface of the enclosed module due to moisture transport \\ through the housing material.
}

Having a model that can predict moisture transport through any housing material configuration would allow for designers to understand the humidity condition on the enclosed electronics' surface and modify the enclosure or electronics design to be able to function properly under the required environmental conditions. The application of the model is limited to isothermal cases (such as certain accelerated testing environments), and more study should be done to predict moisture transport behavior in non-isothermal loading cases. 


\section{References}

[1] J.-C. Cigal and G. Shuttleworth. (2017). The automotive electronics market: A view from a material supplier.

[2] S. Abdelhamid, H. Hassanein, and G. Takahara, "Vehicle as a resource (VaaR)," IEEE Network, vol. 29, no. 1, pp. 12-17, 2015.

[3] C. M. Tan, U. Narula, and D. Kapoor, "Reliability paradox for worldwide automotive electronics," in Reliability and Maintainability Symposium (RAMS), 2017 Annual, 2017, pp. 1-7: IEEE.

[4] A. B. E. S. E. Team. (09/21/2018). Future advances in body electronics. Available: $\quad$ http://www.nxp.com/assets/documents/data/en/whitepapers/BODYDELECTRWP.pdf

[5] G. Leen and D. Heffernan, "Expanding automotive electronic systems," Computer, vol. 35, no. 1, pp. 88-93, 2002.

[6] V. v. Tils, "Design Requirements for Automotive Reliability," Robert BOSCH GmbH2006, Available: http://wwwg.eng.cam.ac.uk/robuspic/pub_present/ESSDERC06/6-ROBUSPICWorkshop-ESSDERC06-VVonTils.pdf.

[7] P. Pickering. (2016). The Rising Popularity of Composite Enclosures. Available: https://www.ecnmag.com/article/2016/03/rising-popularity-compositeenclosures

[8] J. O'Keefe. (2015). Composite enclosures combine light weight with shielding effectiveness. Available: https://www.sae.org/news/2014/01/compositeenclosures-combine-light-weight-with-shielding-effectiveness

[9] T. M. Pelsoci, Composites Manufacturing Technologies: Applications in Automotive, Petroleum, and Civil Infrastructure Industries. US Department of Commerce, National Institute of Standards and Technology, 2004.

[10] L. Sang, C. Wang, Y. Wang, and W. Hou, "Effects of hydrothermal aging on moisture absorption and property prediction of short carbon fiber reinforced polyamide 6 composites," Composites Part B: Engineering, vol. 153, pp. 306314, 2018.

[11] M. Habibi, L. Laperrière, and H. M. Hassanabadi, "Effect of moisture absorption and temperature on quasi-static and fatigue behavior of nonwoven flax epoxy composite," Composites Part B: Engineering, vol. 166, pp. 31-40, 2019.

[12] G. Koronis, A. Silva, and M. Fontul, "Green composites: a review of adequate materials for automotive applications," Composites Part B: Engineering, vol. 44, no. 1, pp. 120-127, 2013.

[13] T. Peret, A. Clement, S. Freour, and F. Jacquemin, "Effect of mechanical states on water diffusion based on the free volume theory: numerical study of polymers and laminates used in marine application," Composites Part B: Engineering, vol. 118, pp. 54-66, 2017.

[14] X.-J. Fan and E. Suhir, Moisture sensitivity of plastic packages of IC devices. Springer, 2010.

[15] B. Gebhart, Heat conduction and mass diffusion. McGraw-Hill, 1993. 
[16] B. Han and D.-S. Kim, "Moisture Ingress, Behavior, and Prediction Inside Semiconductor Packaging: A Review," Journal of Electronic Packaging, vol. 139, no. 1, p. 010802, 2017.

[17] J. Crank, The mathematics of diffusion. Oxford university press, 1979.

[18] T. L. Bergman, F. P. Incropera, D. P. DeWitt, and A. S. Lavine, Fundamentals of heat and mass transfer. John Wiley \& Sons, 2011.

[19] S. Yoon, B. Han, and Z. Wang, "On moisture diffusion modeling using thermalmoisture analogy," Journal of Electronic Packaging, vol. 129, no. 4, pp. 421426, 2007.

[20] C. Jang, A. Goswami, and B. Han, "Hermeticity evaluation of polymer-sealed MEMS packages by gas diffusion analysis," Journal of Microelectromechanical Systems, vol. 18, no. 3, pp. 577-587, 2009.

[21] C. Jang, S. Park, B. Han, and S. Yoon, "Advanced thermal-moisture analogy scheme for anisothermal moisture diffusion problem," Journal of Electronic Packaging, vol. 130, no. 1, p. 011004, 2008.

[22] A. A. Tay and T. Lin, "Moisture diffusion and heat transfer in plastic IC packages," IEEE Transactions on Components, Packaging, and Manufacturing Technology: Part A, vol. 19, no. 2, pp. 186-193, 1996.

[23] N. Peter, P. Toth, B. Kovács, and G. Kristóf, "Implementation of moisture diffusion model in multi-material system including air cavities," in 2016 22nd International Workshop on Thermal Investigations of ICs and Systems (THERMINIC), 2016, pp. 224-229: IEEE.

[24] C. Jang and B. Han, "Modeling of moisture diffusion and moisture-induced stresses in semiconductor and MEMS packages," in Moisture Sensitivity of Plastic Packages of IC Devices: Springer, 2010, pp. 181-219.

[25] E.-H. Wong and R. Rajoo, "Moisture absorption and diffusion characterisation of packaging materials - advanced treatment," Microelectronics Reliability, vol. 43, no. 12, pp. 2087-2096, 2003.

[26] G. Marom and J. Comyn, "Polymer Permeability," Belfast University Press, Belfast, vol. 341, p. 460, 1985.

[27] B. Flaconneche, J. Martin, and M. Klopffer, "Transport properties of gases in polymers: experimental methods," Oil \& Gas Science and Technology, vol. 56, no. 3, pp. 245-259, 2001.

[28] (2019). Standard Permeation Rate Testing. Available: https://www.mocon.com/consulting-and-testing-services/standard-permeationtesting.html

[29] E. C. Suloff, "Sorption behavior of an aliphatic series of aldehydes in the presence of poly (ethylene terephthalate) blends containing aldehyde scavenging agents," Virginia Tech, 2002.

[30] X. Jiang, H. Kolstein, and F. S. Bijlaard, "Moisture diffusion in glass-fiberreinforced polymer composite bridge under hot/wet environment," Composites Part B: Engineering, vol. 45, no. 1, pp. 407-416, 2013.

[31] M. B. Huglin and M. B. Zakaria, "Comments on expressing the permeability of polymers to gases," Die Angewandte Makromolekulare Chemie: Applied Macromolecular Chemistry and Physics, vol. 117, no. 1, pp. 1-13, 1983. 
[32] C.-H. Shen and G. S. Springer, "Moisture absorption and desorption of composite materials," Journal of composite materials, vol. 10, no. 1, pp. 2-20, 1976.

[33] J. E. Galloway and B. M. Miles, "Moisture absorption and desorption predictions for plastic ball grid array packages," IEEE Transactions on Components, Packaging, and Manufacturing Technology: Part A, vol. 20, no. 3, pp. 274-279, 1997.

[34] P. E. Anka Bernnat, Jan Dirlenbach, "Strong in Electronics and Automotive Construction: Polybutylene Terephthalate (PBT)," Kunststoffe international, vol. 2013, no. 10, pp. 67-70, 2013.

[35] B.-G. H. Susumu Fujita. (04/04/2019). Laser Welding: A New Assembling Method for a Production Benefit. Available: http://www2.dupont.com/Hyundai_Kia/en_US/assets/downloads/presentations Laser\%20Welding_Korea_Fujita.pdf

[36] N. Amanat, N. L. James, and D. R. McKenzie, "Welding methods for joining thermoplastic polymers for the hermetic enclosure of medical devices," Medical engineering \& physics, vol. 32, no. 7, pp. 690-699, 2010.

[37] Climate of Singapore. Available: http://www.weather.gov.sg/climate-climateof-singapore/

[38] Climate \& Weather Averages in Kuwait City, Kuwait. Available: https://www.timeanddate.com/weather/kuwait/kuwait-city/climate 